NBER WORKING PAPER SERIES

\title{
TECHNOLOGY ADOPTION AND MARKET ALLOCATION: THE CASE OF ROBOTIC SURGERY
}

\author{
Danea Horn \\ Adam Sacarny \\ R. Annetta Zhou \\ Working Paper 29301 \\ http://www.nber.org/papers/w29301 \\ NATIONAL BUREAU OF ECONOMIC RESEARCH \\ 1050 Massachusetts Avenue \\ Cambridge, MA 02138 \\ September 2021
}

We thank Amitabh Chandra, Timothy Beatty, Pinar Karaca-Mandic, Richard Sexton, Monica Singhal, seminar participants at NBER Health Economics Boot Camp and session participants at the American Society of Health Economics virtual conference for their helpful comments. We thank Maurice Dalton, Mohan Ramanujan, and Jean Roth for their assistance with CMS data. We gratefully acknowledge support from the National Institute on Aging P01-AG005842. The authors declare that they have no relevant or material financial interests that relate to the research described in this paper. This research was approved by the Institutional Review Boards of Columbia University and the National Bureau of Economic Research. The views expressed herein are those of the authors and do not necessarily reflect the views of the National Bureau of Economic Research.

At least one co-author has disclosed additional relationships of potential relevance for this research. Further information is available online at http://www.nber.org/papers/w29301.ack

NBER working papers are circulated for discussion and comment purposes. They have not been peer-reviewed or been subject to the review by the NBER Board of Directors that accompanies official NBER publications.

(C) 2021 by Danea Horn, Adam Sacarny, and R. Annetta Zhou. All rights reserved. Short sections of text, not to exceed two paragraphs, may be quoted without explicit permission provided that full credit, including $\odot$ notice, is given to the source. 
Technology Adoption and Market Allocation:The Case of Robotic Surgery

Danea Horn, Adam Sacarny, and R. Annetta Zhou

NBER Working Paper No. 29301

September 2021

JEL No. I1,L1

\begin{abstract}
$\underline{\text { ABSTRACT }}$
The adoption of healthcare technology is central to improving productivity in this sector. To provide new evidence on how technology affects healthcare markets, we focus on one area where adoption has been particularly rapid: surgery for prostate cancer. Over just six years, robotic surgery grew to become the dominant intensive prostate cancer treatment method. Using a difference-in-differences design, we show that adopting a robot drives prostate cancer patients to the hospital. To test whether this result reflects market expansion or business stealing, we also consider market-level effects of adoption and find they are significant but smaller, suggesting that adoption expands the market while also reallocating some patients across hospitals. Marginal patients are relatively young and healthy, inconsistent with the concern that adoption broadens the criteria for intervention to patients who would gain little from it. We conclude by discussing implications for the social value of technology diffusion in healthcare markets.
\end{abstract}

Danea Horn

University of California at Davis

dmhorn@ucdavis.edu

Adam Sacarny

Mailman School of Public Health

Columbia University

722 West 168th Street

New York, NY 10032

and NBER

ajs2102@columbia.edu
R. Annetta Zhou

RAND Corporation

azhou@rand.org 


\section{Introduction}

The healthcare sector accounts for almost one-fifth of the U.S. economy, a share that has grown dramatically in the last quarter-century (CMS, 2020b). Technology adoption in health care is a key determinant of productivity in this sector, and technology is widely considered the central driver of long-term productivity gains in the broader economy (Jorgenson, 2011). However, unique features of the healthcare sector, like information frictions and insurance, can distort the quality and quantity of technology adoption. If patients or their agents (such as referring physicians) have a preference for technology or use it as a proxy for quality, the introduction of a new technology will increase demand and prompt adoption by care providers. New technology has the potential to promote a wave of adoption as hospitals compete over the same set of patients, resulting in service duplication and increased cost. In this way, adoption could theoretically go beyond the socially optimal level, a phenomenon known in health care as the "medical arms race."

In this study, we ask how technology adoption impacts utilization of hospital care to better understand its role in the performance of the healthcare sector. We use the diffusion of robotic surgery for the treatment of prostate cancer to investigate how patients or their agents respond. Adoption of surgical robotics proceeded exceptionally rapidly: from its introduction in 2001 through 2015, more than half of hospitals in the U.S. that treat cancer patients adopted a robot (Figure 1). Focusing on surgical removal of the prostate, termed prostatectomy, allows us to assess how patient volume changes in response to a new technology from inception along its trajectory to becoming the predominant method of intensive intervention for these patients. Additionally, surgical robots are a frequent focus of hospital

advertising, pointing toward their potential use by patients as a signal of quality Schwartz and Woloshin, 2019; Sheetz et al., 2020).

Our differences-in-differences research design exploits variation in the timing of adoption across hospitals in the U.S. to estimate the effect of robotic surgery on patient volume 
and characteristics. We show that adoption leads to a statistically significant and economically meaningful rise in hospital volume: prostate cancer admissions (the risk set for robotic surgical intervention) increase by 59 log points and prostatectomies (in which the robot can be used) increase by 69 log points. In event study plots, we show that these estimates average over effects that increase over time. These results suggest that patients - or their agents have a preference for robotic surgery or view it as as signal of quality.

Increases in patient admissions would arise if robotic device adoption expands the market for robotic surgery. On the other hand, our estimates are also consistent with business stealing in which hospitals adopt surgical robots to compete over the same patients. To distinguish between market expansion and business stealing, we also implement our research design at the healthcare market level. We show that as hospitals in a market adopt surgical robots, the volume of prostate cancer patients and prostatectomies in the entire market rises in response. Surgical robot adoption thus leads to meaningful expansions in the market for intensive intervention. These effects are statistically and economically significant, but are just under half the magnitude of the hospital-level results. Using event study plots to illustrate dynamics of the effects, we find that they grow over time but on a shallower trajectory than their hospital-level counterparts. Taking these findings together, we conclude that some of the hospital-level effects also reflect business stealing in which adoption leads to a re-shuffling of patients.

Our results raise the question of who receives treatment at the margin when a hospital adopts a surgical robot and patient volume expands. We apply our main estimation strategy to study two key characteristics of patients, age and pre-existing burden of illness. We find that adoption of surgical robots brings relatively younger and healthier patients to the hospital for treatment. A key concern is that prostatectomy induced by robot adoption could provide little value to patients and society because the recipients may have short remaining life expectancy (they would likely die of another competing health risk) or have severe existing 
health conditions (they are at a high risk of adverse surgical outcomes) (Lepor, 2000). Our findings reject the idea that surgical robotics is expanding treatment among this group. Thus we find no sign that adoption broadens eligibility criteria for surgical intervention in a way that would attract patients who, at least on observable characteristics, are likely to benefit little from treatment. 1

Robotic surgery is well-suited to the study of healthcare technology and its diffusion for several reasons. First, barriers to entry are relatively low for surgical robots. The initial capital investment of approximately $\$ 2$ million is significantly less than other intensive technologies like cardiac catheterization laboratories which have been the focus of much prior research (Barbash and Glied, 2010; Cutler et al., 2010). Accordingly, the cost of a surgical robot does not trigger certificate of need (CON) laws in most states (Jacobs et al., 2013). Second, whether physicians use a robot for prostate surgery has no bearing on the Medicare physician or hospital payment for the procedure, and evidence for clinical benefit of the robot for prostate cancer treatment relative to non-robotic surgery is essentially nonexistent (Sandoval Salinas et al., 2013, Yaxley et al., 2016; Ilic et al., 2017). The lack of direct financial incentive and clinical benefit points to the potential adoption of surgical robots as a pure signal to patients, rather than an attempt to improve outcomes or bill more for the same cases. Third, Medicare patients are largely protected from the costs of intervention, and so out-of-pocket costs should play little role in the decision to initiate surgery with or without the robot. Finally, robots are sufficiently new that we observe hospital adoption and the universe of Original Medicare prostate cancer patients starting from initial FDA approval.

This study contributes to the literature in three key ways. First, we add to the evidence on the efficiency of technology diffusion in the health care sector. The most relevant prior

\footnotetext{
${ }^{1}$ While these results show that adoption of surgical robots did not lead to the clearest socially wasteful overuse for prostate cancer treatment, we cannot ascertain that the expansion of the intervention to the younger, healthy group is necessarily cost-effective. Such analysis is beyond the scope of this study but an important topic for future work.
} 
studies have focused on the potential for a socially wasteful medical arms race in which hospitals compete for patients by providing care of questionable value and acquiring costly high-tech equipment (Dranove et al., 1992, Kessler and McClellan, 2000). This research is related to the concept that free entry can lead to social inefficiencies through business stealing (Mankiw and Whinston, 1986). As we show, adoption of surgical robots leads to business stealing as well as market expansion, which the literature would interpret as a signpost of an arms race - though the presence of market expansion rules out that adoption was wholly the result of such a phenomenon. Still, the welfare impacts of technology adoption depend on the costs and benefits of the technology for patients who use it at the margin. Our finding that the patients who are induced to get treatment due to the robot are younger and healthier suggests that the worst fears for social inefficiencies were not realized. However, combining our results with clinical literature finding minimal benefits of the robot for patient outcomes calls into question whether this adoption was socially beneficial.

These results also relate to research on productivity variations in the health care sector. Much of this work has focused on the adoption of evidence-based, low-cost technology like beta blockers in the treatment of heart attacks (Skinner and Staiger, 2007; Chandra and Staiger, 2007). Disparities in the use of these technologies are hypothesized to be a key determinant of productivity variations across regions (Baicker and Chandra, 2004, Skinner and Staiger, 2015). The benefits of adopting costly, high-tech equipment for the efficiency of the sector are more equivocal as, for example, Cutler et al. (2010) shows in the case of coronary bypass surgery for heart attacks. We add new evidence on the adoption of costly technology with few de jure restrictions on adoption and even less evidence backing its use. As we show, the surgical robot drove large volumes of patients to the hospital even as its clinical value remained unsubstantiated.

Finally, our work connects research on demand responses to quality information with the literature on hospital market responses to technology adoption. One piece of conven- 
tional wisdom suggests that unique characteristics of the health care market, such as the lack of accurate quality information and the prevalence of insurance coverage, dampens demand-side competition and gives providers little incentive to innovate (Cutler et al., 2010, Skinner, 2011). More recent studies challenge this view and show evidence that the allocation of patient volume across hospitals does respond to quality information (Chandra et al. 2016). Recent developments in health care markets like increased public reporting of patient outcomes may make the demand response to quality, or perceived quality, even stronger. The strong volume increases we see in response to innovation demonstrates that there can be strong demand-side competition in health care. Our results suggest that patients and their agents view hospitals that have adopted the robot as higher quality and thus more preferable. This robust response to innovation has been found in technologies relating to treatments for cardiovascular disease, but the magnitude is not as stark as what we have found here (Hodgkin, 1996; Grossman and Banks, 1998).

The paper continues as follows: Section 2 provides background on robotic surgery devices and prostate cancer. Section 3 presents the data used in the analysis. Section 4 describes the estimation methodologies. Section 5 details the results. Section 6 discusses the findings and concludes.

\section{Background}

Robotic assisted surgical devices were first introduced to the general U.S. hospital setting in 2000 when Intuitive Surgical, Inc. received FDA approval to bring its da Vinci device to market. Due to patent protection, the da Vinci surgical robot remained the only surgical robot available in the U.S. through our analysis period.2 This device augments laparoscopic surgery, assisting physicians in procedures conducted through small incisions (Mack, 2001).

\footnotetext{
${ }^{2}$ Intuitive Surgical faced one major competitor, Computer Motion, Inc., whose ZEUS surgical-robotic system received FDA approval in 2001. After patent battles, the firms merged in 2003 and ZEUS was removed from the market (SEC, 2003).
} 
Robotics aim to expand a surgeon's capabilities by increasing their dexterity, flexibility and visual field. During a robot-assisted procedure the surgeon sits at a console and controls robotic arms with specially-designed instruments. In contrast, in traditional laparoscopic surgery the physician would manipulate instruments directly.

Purchasing a robotic surgical system requires an initial capital investment of approximately $\$ 2$ million, and robotic procedures cost hospitals an average of 13 percent more than traditional laparoscopic surgery (Barbash and Glied, 2010). However, Medicare hospital and physician reimbursement do not differentiate between robotic surgery and laparoscopic surgery (the reimbursement systems are agnostic to the surgical instrument, though pay differs more invasive open procedures). Given Medicare's tendency to reimburse at average rather than marginal cost, robot adoption and use can still be profitable for hospitals, particularly if the device receives heavy use. Hospitals may thus seek to increase the volume of procedures after adoption (Sheetz et al., 2020). Perhaps unsurprisingly given the appeal of a volume-oriented strategy, hospitals heavily advertise their surgical robots (Schwartz and Woloshin, 2019).

We focus on robotics in the context of prostate cancer because the robot has played a notably large role in transforming how prostatectomy is performed in comparison to other conditions intensively treated with the robot (Chandra et al., 2011). Prior to robotics, prostatectomy was usually an open-site procedure because the prostate is hard to access with a laparoscope (Finkelstein et al. 2010). Figure 2 shows that by 2008, just 8 years after the FDA approval of the robot, open-site procedures were no longer the dominant method of prostatectomy. The market implications of this phenomenon have received surprisingly little study; perhaps the most relevant work in this area is Ko and Glied (2021), which found that hospital robot adoption increased robot use and decreased costs for New York state Medicaid patients.

The transition to laparoscopic intervention was driven by adoption of the robots, and we 
exploit this rapid roll-out in our differences-in-differences research design. Yet this dramatic change in intervention modality was backed by essentially no randomized trial data. To date, only one randomized trial has compared the robotic and open approaches head-to-head; it was published after our sample period and detected no benefit of the robotic approach (Yaxley et al. 2016). Systematic reviews of randomized trials find that the outcomes of open, laparoscopic, and robotic prostatectomy are similar (Sandoval Salinas et al., 2013; Ilic et al., 2017).

Prostate cancer is the second most common cancer behind skin cancer in men and results in approximately 33,000 deaths each year (ACS, 2020, CDC, 2020). Prostatectomy, or the removal of the prostate gland, is the key surgical treatment for prostate cancer. However, the treatment can come with significant side effects like incontinence and sexual dysfunction that may dramatically impact a patient's life. The high personal and accounting costs of aggressively treating this slow-growing cancer has led to a shift toward a watch-andwait strategy to avoid over-treating a disease that may not become fatal (Lepor, 2000). Prostatectomy hospitalizations decreased by 32 percent in Medicare over our sample period as watch-and-wait became more widespread in managing prostate cancer (Appendix Figure A1). The introduction of robots overlays this reduction in aggressively treating prostate cancer, and so increases in prostatectomy volume induced by surgical robots may only partially offset the general decline in intensive intervention.

\section{Data}

The key allocation analyses in this study measure the volume of prostate cancer and prostatectomy inpatients at each hospital in each year. Both volume measures are key to this study because adoption of a surgical robot could attract patients to the hospital whether or not they ultimately receive surgical intervention; they provide, respectively, a broader and narrower view of the impact of adoption on allocation. We source these measures from 1998- 
2015 inpatient hospitalization records (called MEDPAR) for 100\% of Medicare beneficiaries ${ }^{3}$ We count patients with a principal diagnosis of prostate cancer and, separately, those with prostate cancer who also received a prostatectomy. Appendix Table A1 lists the diagnosis and procedure codes we use to identify patients. When we analyze patient characteristics, we do so through a linkage to patient summary data (the Master Beneficiary Summary File). We omit patients under age 65, who can enter Medicare due to disability or end-stage renal disease, to focus on the older adult population for whom coverage is near-universal. We also exclude managed care patients, for whom reporting is incomplete, from all analyses.

To observe if and when hospitals acquire surgical robots, we rely on snapshots of the Intuitive Surgical website posted on the Wayback Machine (archive.org) from 2002-2005 and American Hospital Association (AHA) survey data from 2005-2015. Our first view of adoption thus occurs 12 to 18 months after the robot was approved by the FDA. To account for the lag between very early adoption and initial reporting, we assign hospitals listed in the 2002 archive of the website an adoption year of 2001.

The Medicare setting has a number of advantages for this research. The size of the program allows us to observe patient allocation in essentially all U.S. markets and the vast majority of hospitals. The Original Medicare program imposes no network restrictions on patients. The cost-sharing structure of Medicare and patients' frequent enrollment in secondary coverage of these costs mean that patients have little financial incentive to choose one hospital over another. Together, these features of Medicare insulate our findings from potentially endogenous changes in networks and cost-sharing that might occur in private insurance.

Our analysis period spans 1998 through 2015. All analyses presented in this study use

\footnotetext{
${ }^{3}$ We focus on inpatient stays because Medicare only covers open and robotic/laparoscopic prostatectomy in this setting during our analysis period (CMS, 2015). A related procedure, transurethral resection of the prostate (TURP), is covered in the outpatient setting but is most often used to treat an enlarged prostate as opposed to prostate cancer (Hopkins, 2021). In more recent years post-dating our analysis period, Medicare began expanding its coverage of prostatectomy procedures in the outpatient setting (CMS, 2020a).

${ }^{4}$ The FDA approved the da Vinci surgical robot on July 17, 2000 (FDA, 2000)
} 
a balanced panel of hospitals that treated at least 1 patient with any condition in every year $5^{5}$ To ensure we observe at least 3 years of pre- and post-adoption patient volumes at all facilities, hospital-level analyses omit facilities that acquire a robot after 2012. We also restrict to the plausible hospital choice set for patients seeking cancer care. First, we limit to short-term and critical access hospitals. Second, hospitals in the analysis sample must admit a minimum of 50 patients annually with at least 5 of those patients being admitted for cancer treatment (we do not count skin cancer). In robustness analyses we show that our findings are preserved when we add back late adopters and facilities that fail to meet the patient thresholds. ${ }^{6}$

Table 1 provides summary statistics for the 2,261 hospitals in our sample, split nearly evenly into those that do and do not adopt. Compared to non-adopters, hospitals that adopt a robot tend to be larger, in urban areas and are more often teaching institutions. Adopters also treat more cancer patients overall and treat more prostate cancer patients. In turn, adopting hospitals also have three to four times the prostate cancer and prostatectomy market shares of non-adopting hospitals. These differences may partly reflect the effect of robot adoption itself in driving these patients to the hospitals.

\section{Analytic Approach}

Our research design exploits the staggered adoption of surgical robots across hospitals to identify the effect of acquiring a robot on patient volume and characteristics. We conduct analyses at the hospital and market levels. Analyses at the latter level are key to evaluating the market-expanding effect of surgical robots because there is less scope for patients to

\footnotetext{
${ }^{5}$ To ensure that hospitals that change Medicare provider numbers are consistently tracked, we draw on a provider number transition matrix graciously provided to us by Jon Skinner and the Dartmouth Institute for Health Policy and Clinical Practice. We map together all provider numbers that ever refer to the same facility into one synthetic hospital. A synthetic hospital is considered to have adopted a robot if any of its component provider numbers has adopted one.

${ }^{6}$ The hospitals in our main analysis sample capture 87 percent of all Original Medicare prostate cancer patients and 88 percent of all prostatectomy patients. The expanded set of hospitals analyzed in the robustness section captures 94 percent of prostate cancer patients and 95 percent of prostatectomy patients.
} 
reallocate across markets than across hospitals. When analyses at the hospital-level show stronger allocation effects than those at the market-level, it suggests the presence of business stealing since patients have more scope to change the hospital where they receive treatment within a market.

We implement this research design at the hospital level by estimating differences-indifferences Poisson regressions of the following form:

$$
N_{h t}=\exp \left(\alpha_{t}+\alpha_{h}+\beta \cdot \text { interim }_{h t}+\gamma \cdot \text { post }_{h t}+X_{h t} \Omega\right)+\varepsilon_{h t},
$$

where $h$ and $t$ index hospitals and years, respectively. The outcome $N_{h t}$ is a measure of patient volume; $\alpha_{t}$ and $\alpha_{h}$ are year and hospital fixed effects, respectively; interim indicates $_{h t}$ whether the hospital adopted the robot in year $t$; post $_{h t}$ indicates whether the hospital adopted the robot in year $t-1$ or earlier; and $X_{h t}$ is a vector of time-varying hospital controls. Our primary analyses include no controls in $X_{h t}$, but in robustness analyses we show our results are similar as we add controls of varying richness. The key coefficient of interest is $\gamma$, the log-point effect of adopting a robot on volume omitting the initial adoption year. This log-point interpretation is similar to that of a log-linear model.

The identifying assumption of this model is that absent acquiring a surgical robot, adopters and non-adopters would have followed common proportional trends in patient volume. Equivalently, it assumes that patient volume at adopters and non-adopters would have grown at common rates. To this end, we run event-study specifications:

$$
\begin{array}{r}
N_{h t}=\exp \left(\alpha_{t}+\alpha_{h}+\delta_{-3} a d o p t_{h, t-3}^{p r e}+\gamma_{-2} a_{\text {adopt }}{ }_{h, t-2}+\ldots+\gamma_{2} a_{\text {adopt }}+,+2+\delta_{3} a d o p t_{h, t+3}^{\text {post }}\right) \\
+\varepsilon_{h t},
\end{array}
$$

where $a d o p t_{h, t-k}^{p r e}$ indicates that the hospital adopted robotics in year $t-k$ or earlier, $a_{d o p t} t_{h, t}$ indicates adoption in year $t$, and $a d o p t_{h, t+k}^{\text {post }}$ indicates adoption in year $t+k$ or later. We 
omit dopt $_{h, t-1}$ as the reference year. This specification emits pre-trend coefficients $\left(\delta_{-3}, \delta_{-2}\right)$ to test if volume grew at common rates before adoption, a key falsification exercise for the counterfactual parallel trends assumption. It also yields post-adoption coefficients $\left(\delta_{0}, \ldots, \delta_{3}\right)$ illustrating the dynamics of the impacts.

The Poisson model has several advantages for our setting. First, compared to a loglinear regression, it accommodates zeroes without adding an arbitrary constant or switching to an alternative functional form like inverse hyperbolic sine (though we show that our findings are preserved under such alternatives). Second, unlike the bulk of nonlinear models it is robust to fixed effects, which we use in our core models and (in higher dimensional form) in our robustness exercises (Hausman et al., 1984). Finally, the model makes few assumptions about the data-generating process beyond that the conditional mean takes the form in equations 1 and 2 it does not require that $N_{h t}$ is Poissonian much as linear regression does not require the outcome to be normally distributed (Gourieroux et al., 1984; Wooldridge, 1999).

We also run the models given by equations 1 and 2 at the market level, replacing all hospital subscripts $h$ with market subscripts $r$. As a market concept, we use Dartmouth Hospital Referral Regions (HRRs), which partition the U.S. into 306 regions within which patients tend stay when they receive specialty care. The outcome $N_{r t}$ counts patient volume at all hospitals in the market rather than at one hospital. To measure market-wide adoption of the robot, we define interim $_{r t}$ as the beds-weighted share of hospitals in market $r$ that adopted the robot in year $t$ and post $_{r t}$ as the beds-weighted share of hospitals that adopted the robot in year $t-1$ or earlier. For the event study we define the adopt $t_{r t}$ variables analogously as the beds-weighted averages of $a_{d o p t}$ across the hospitals in the market. We construct the adoption measures this way to maximize their comparability with the hospitallevel estimates; the market-level coefficients we report give the log-point effect of all hospitals in the market adopting a robot. 


\section{Results}

\subsection{Patient Allocation}

Table 2 presents our main estimates of the effect of robot adoption on patient volume based on equation 1. We focus on $\gamma$, the coefficient on post, which provides a single estimate of the long-term effect of adoption averaging over its dynamics. At the hospital level, adoption raises prostate cancer patient volume unconditional on surgical intervention by 59 log points, an expected absolute increase of 7.8 patients per year at the average hospital. Prostatectomy patient volume rises $69 \log$ points or 7.6 patients. Effects at the market level are just under half the log-point magnitude. Going from $0 \%$ to $100 \%$ adoption in a market is expected to raise market-wide prostate cancer patient volume by $28 \log$ points (27.8 patients) and prostatectomy patient volume by $34 \log$ points (27.7 patients). All of these effects are highly statistically significant.

Figure 3 plots the event study estimates from equation 2 for prostate cancer volume (Panel A) and prostatectomy volume (Panel B) outcomes. The panels illustrate three key facts. First, they show limited differences in pre-adoption trends in patient volume between adopting and non-adopting hospitals and between relatively slow-adopting and fast-adopting markets, a key falsification exercise for the parallel counterfactual trends assumption of differences-in-differences. Pre-trends are quantitatively small at the hospital level; at the market level they reverse trajectories after adoption, suggesting our findings will be, if anything, conservative.

Second, the effect of adopting a robot on patient volume grows over time. For example, hospital-level prostate cancer patient volume increases by a statistically significant $17 \log$ points in the adoption year, an effect that rises to 73 log points in the third year and beyond. Essentially the same pattern holds for prostatectomy patients, though magnitudes are slightly larger. These results highlight the importance of effect dynamics for patient 
allocation following robot adoption. They suggest that the long-term effect is greater than the single average effect estimated in Table 2.

Third, effects at the market level are also highly significant and growing over time, but they expand on a shallower trajectory than hospital-level effects. The market-level estimates are very roughly half the magnitude of those at the hospital level, much as we found in Table 2. The divergence in magnitudes between the regressions at the two levels informs whether adoption leads to market expansion or business stealing. The economically meaningful and statistically significant market-level impacts suggest that robots expand the market, since there is less scope for patients to be "stolen" across markets. Yet the greater magnitudes at the hospital level imply that adoption further leads to business stealing as patients re-allocate across facilities in the same market.7

\subsection{Robustness}

Appendix Tables A2 and A3 provide a number of robustness checks on the hospital-level prostate cancer and prostatectomy results, respectively. The tables first test adding varying controls to the baseline estimating equation 1. Our key findings are preserved when adding hospital-specific trends, hospital size decile-by-year interactions, and market by year interactions (effects attenuate somewhat with the inclusion of trends and expand somewhat when controlling for markets). We also consider controls for rest-of-market robot adoption to directly model the potential for one hospital's adoption to attract patients away from other facilities. Point estimates on the rest-of-market coefficients are negative, as expected, but own-adoption effects are unchanged.

The tables next test robustness to alternative hospital samples. In a more restrictive approach, we limit the sample to adopters so that identification comes solely from comparing

\footnotetext{
${ }^{7}$ The market-level estimates report the effect of $100 \%$ of hospitals in a market adopting to make them comparable to the hospital-level estimates. Since the typical market has lower levels of adoption, the effect of surgical robots on total volume would be attenuated accordingly.
} 
hospitals that acquired a robot early vs. late in the period. Estimates shrink somewhat but remain highly economically and statistically significant 8 Results are qualitatively unchanged from baseline when we use the broadest sample possible by including hospitals that acquired a robot after 2012 as well as those that failed to meet the minimum total patient and cancer patient thresholds. We additionally test robustness to alternative functional forms by running linear regressions with $\ln \left(N_{h t}+1\right)$ and $\operatorname{asinh}\left(N_{h t}\right)$ as the outcomes, respectively. Our results are little changed under these alternatives.

Appendix Tables A4 and A5 report robustness checks for the market-level analyses. Effects remain significant with the inclusion of market-specific trends, and while they attenuate somewhat, the ratios of these effects to their hospital-level analogs reported in the prior robustness tables remain similar. We also show estimates nearly identical to those reported in the main text when we calculate market-level patient volume and adoption rates from the broadest possible set of hospitals (adding those that had failed to meet minimum patient and cancer patient thresholds). Finally, we provide estimates from linear models which yield significant (albeit expanded) coefficients.

\subsection{Characteristics of Marginal Patients}

Having demonstrated substantial increases in patient volume in response to robot adoption, we now analyze the characteristics of the marginal patients drawn in to treatment. We focus on prostatectomy patients for brevity and since their hospital stay makes direct use of the robot; results for prostate cancer yield essentially identical patterns and are presented in Appendix Table A6. We characterize patients on two dimensions, each key for assessing their suitability for surgical intervention: age and burden of illness. We measure illness by

\footnotetext{
${ }^{8}$ One reason for this attenuation may be that restricting the sample puts more weight on the short-term effects of adoption, which are smaller according to the event studies. To explore this concern, we model the adoption effect dynamics as having a constant (given by $\gamma$, as before) and a linear slope (we add the interaction post $_{h t} \times\left[t-\right.$ adoptyear $\left._{h}-1\right]$, where the bracketed term is the hospital's adoption year relative to the post period). Columns 10 and 11 of Appendix Tables A2 and A3 augment the baseline and adopters-only models, respectively, with this interaction. The results are consistent with this concern: the constant terms converge and the slope terms are similar between the models.
} 
counting the number of chronic conditions (CCs) according to the patients diagnoses prior to the hospitalization. 9

Figure 4 plots the coefficient $\gamma$ on post from estimating equation 1 with the outcome redefined as the number of prostatectomy patients in the specified age or CC bin (Appendix Figure A2 presents the results for prostate cancer). The volume increases at both the hospital and market levels are driven by younger patients. At both levels, effects attenuate greatly as the age bin rises; at the market-level we fail to detect effects at age 75 and up and point estimates are close to zero for ages 80 and up.

Effects by history of illness follow an upside-down U-shaped path. At both the hospital and market levels we detect significant increases in the volume of patients with up to $4 \mathrm{CCs}$, those with low and intermediate levels of prior illness. Point estimates for the volume of patients with no CCs, those who are observably the healthiest, are slightly smaller. Effects on the volume of patients with 5 or more CCs are the smallest; they are still significant at the hospital level but not the market level.

To provide a sense of how the patients induced to receive treatment due to robot adoption compare to incumbent patients, we directly estimate the effect of adoption on the average characteristics of the patients. Our approach draws on Gruber et al. (1999) and adapts their two stage least squares method to our context, which uses a Poisson model. Specifically, for each patient characteristic of interest we estimate two Poisson regressions: a first stage on patient volume, which repeats equation 1, and a reduced form with the same specification but the outcome redefined as the average characteristic of patients at the hospital or in the market. We then report the first stage estimates, which repeat our prior volume findings; the reduced form estimates, which indicate the log point effect of adoption on the average characteristic of the patients; and the ratio of the reduced form to the first

\footnotetext{
${ }^{9}$ We track $22 \mathrm{CCs}$ measured in the Medicare Chronic Conditions data at 6-month intervals using the observation most immediately predating the patient's admission. This data was not available before 1999 so these estimates are limited to the years 2000 to 2015.
} 
stage, similar to an indirect least squares estimate. As the ratio of two log-point effects, this object is an elasticity. Under the assumption that adopting a surgical robot brings new patients into treatment without pushing old patients out of treatment (i.e. there are no "defiers" to adoption), the elasticity can be interpreted as the log point difference in the average characteristic between marginal patients and the incumbents. Appendix A provides more details on this model.

Table 3 reports the estimates from these regressions. Panel A reports the first stage with similar estimates to those presented earlier (when they differ, it is because we omit observations where the average characteristic could not be calculated, e.g. when a hospital or market has no patients or the characteristic is not observed). Panel B reports the reduced forms. Columns 1-4 show the effect of adoption on average age and CCs. As expected, adoption tends to lower the age of the average patient at both the hospital and market level. For example, when a hospital adopts, average patient age is expected to fall by $2.9 \log$ points or 2.1 years off the average; when $100 \%$ of a market adopts, average age falls by $2.3 \log$ points or 1.6 years off the average. Panel $\mathrm{C}$ scales the reduced form by the first stage. These elasticities indicate that the marginal prostatectomy patient is statistically significantly 5.4 log points younger at the hospital level (3.9 years off the average) and 6.7 log points younger at the market level (4.7 years off the average) than the incumbents. Results on CCs indicate that marginal patients are healthier, with elasticities that are 4-5 times larger than age elasticities at both levels but only statistically significant at the hospital level.

These results suggest that markets and hospitals grow in response to robot adoption by attracting younger, healthier prostate cancer patients. The attraction to robotics does not seem to be as strong for relatively sick patients. These findings imply that the influx of patients after adoption is not caused by widening eligibility criteria to patients in observably poorer health, particularly on the basis of age.

In columns 5-7 of Table 3 we consider how adoption changed the features of the average 
hospital in a market performing prostatectomy. Specifically, we test if markets that adopt tend to shift their prostatectomy patients to larger, higher-volume, and teaching hospitals.10 The directions of these effects are a priori unclear: adoption by large well-resourced hospitals could further entrench their market dominance while adoption by smaller hospitals could give them a new opportunity to compete with their larger counterparts. While we do not find any significant effects on these metrics, the point estimates are all positive indicating that if there is adjustment in response to adoption it tends to concentrate patients at bigger hospitals with teaching infrastructure.

\section{Discussion and Conclusion}

Robotic surgery diffused quickly through the health care system, and during our analysis period it became the primary surgical modality to treat prostate cancer. Our results clearly indicate that when hospitals adopt this technology they attract more prostate cancer patients. We find signs that this increase in patient volume occurs through both business stealing and market expansion following adoption. As hospitals in a market adopt surgical robots, prostate cancer volume increases in the whole market; since it is relatively difficult to "steal" patients across regions, this result shows the market-expanding power of surgical robots. Still, this phenomenon does not explain the totality of the increase in volume that occurs after a hospital adopts, since we find a hospital-level effect that is roughly twice the market-level effect. The gap between the results at each level points to a significant role for business stealing.

The welfare implications of this result are nuanced. One interpretation of these findings is that they indicate a wasteful medical arms race, since hospitals had few regulatory constraints on adoption, frequently took up a new technology with nontrivial fixed costs, and engaged in business stealing from one-another. If hospitals do not otherwise differ in

\footnotetext{
${ }^{10}$ To ease interpretation, we measure hospital size and volume at baseline (1998) levels, which avoids exploiting growth in size and volume due to adoption of the robot itself.
} 
their quality of care, this service duplication could be welfare-damaging. However, when hospitals differ in quality, business stealing has the potential to improve — or further reduce — welfare by redirecting patients to better or worse hospitals. For example, outcomes from robotic surgery are widely believed to depend on provider experience with the device (Savage and Vickers, 2009). If low-volume facilities attract patients by adopting robots, patient outcomes could deteriorate throughout the market because provider experience could become more diluted. On the other hand, if facilities that adopt robots tend to be higher-performing, the marginal patients attracted to them could benefit. Such a channel may operate here: adopting hospitals tend to be bigger and are more likely to be teaching facilities, two features that are associated with better patient outcomes (see e.g. Birkmeyer et al., 2002, Burke et al., 2017); we also note signs in Section 5.3 that as markets adopt, patients are more likely to receive treatment at these facilities.

Market expansion is generally considered a sign of welfare improvement in traditional sectors, since a rise in quantity would tend to signal more consumers with access to the good. The market imperfections typical of the health care sector add some complication to this interpretation, however. Market expansion may be welfare-decreasing if it occurs due to moral hazard, when patients or their agents are shielded from the true costs of the technology due to insurance and overuse it as a result, or from behavioral hazard, when patients or their agents are attracted to hospitals with robotics because they have biased beliefs about the benefits of the technology (Baicker et al., 2015).

A full accounting of these welfare effects would require detailed clinical data on patient characteristics like cancer staging. Still, the relatively coarse data that we observe in claims is informative for ruling out a key welfare-damaging moral and behavioral hazard story in which poor candidates for intensive treatment are attracted to the hospital after adoption. During our analysis period, prostate cancer treatment guidelines increasingly sought to discourage older patients with competing risks from intensive testing for and management of 
this condition (USPSTF, 2008; Lepor, 2000). We find that the increase in prostatectomy patient volume in response to robot adoption is comprised of relatively younger patients that have fewer chronic conditions; we fail to detect increases in volume for patients age 80 and up or those with 5 or more chronic conditions. Our findings therefore suggest that robot adoption had small-to-nonexistent market-expanding effects on poor matches for surgery, an encouraging though not definitive sign that welfare was not harmed through at least one channel 11

In this study, we sought to evaluate the effects of hospital technology adoption on hospital utilization through the lens of surgical robotics in prostate cancer. We found striking impacts of adoption on patient volume at both the hospital- and market-level. These results raise key questions for future work on robotics and technology in the health care sector. While robotics has diffused particularly rapidly in prostate cancer treatment, its welfare effects in other areas of health care remain an open question that merits further study. In the space of prostate cancer treatment, future work could exploit electronic medical record or cancer registry data to observe an even richer view of patient outcomes. Taken together, our work highlights the power of technology diffusion to rapidly change the health care delivery system with concomitant implications for patient welfare.

\section{References}

ACS (2020). Facts \& Figures 2020: Key Statistics for Prostate Cancer. Atlanta, GA.

Baicker, K. and A. Chandra (2004). Medicare Spending, The Physician Workforce, And Beneficiaries' Quality Of Care: Areas with a high concentration of specialists also show higher spending and less use of high-quality, effective care. Health Affairs 23(Suppl1), W4-184. Publisher: Project HOPE-The People-to-People Health Foundation, Inc.

\footnotetext{
${ }^{11}$ While we can rule out that marginal patients are poor candidates because they are relatively old or have competing risks, we cannot determine if they have early-stage prostate cancer and are seeking aggressive (and potentially low-value) treatment. Such analyses would require electronic medical record or cancer registry data and are an important topic for future study.
} 
Baicker, K., S. Mullainathan, and J. Schwartzstein (2015, November). Behavioral Hazard in Health Insurance. The Quarterly Journal of Economics 130(4), 1623-1667.

Barbash, G. I. and S. A. Glied (2010). New Technology and Health Care Costs - The Case of Robot-Assisted Surgery. New England Journal of Medicine 363(8), 701-704.

Birkmeyer, J. D., A. E. Siewers, E. V. Finlayson, T. A. Stukel, F. L. Lucas, I. Batista, H. G. Welch, and D. E. Wennberg (2002, April). Hospital Volume and Surgical Mortality in the United States. New England Journal of Medicine 346(15), 1128-1137.

Burke, L. G., A. B. Frakt, D. Khullar, E. J. Orav, and A. K. Jha (2017, May). Association Between Teaching Status and Mortality in US Hospitals. JAMA 317(20), 2105.

CDC (2020). Prostate Cancer Statistics. Technical report, CDC: Division of Cancer Prevention and Control.

Chandra, A., D. Cutler, and Z. Song (2011). Who Ordered That? The Economics of Treatment Choices in Medical Care. In Handbook of Health Economics, Volume 2, pp. 397-432. Elsevier.

Chandra, A., A. Finkelstein, A. Sacarny, and C. Syverson (2016). Health Care Exceptionalism? Performance and Allocation in the US Health Care Sector. American Economic Review 106(8), 2110-2144.

Chandra, A. and D. Staiger (2007). Productivity Spillovers in Health Care: Evidence from the Treatment of Heart Attacks. Journal of Political Economy 115(1), 103-140.

CMS (2015). Hospital Outpatient Regulations and Notices: Addendum E: Final HCPCS Codes That Are Paid Only as Inpatient Procedures for CY 2015. Technical Report CMS1613-FC, Centers for Medicare \& Medicaid Services.

CMS (2020a). CY 2021 Medicare Hospital Outpatient Prospective Payment System and 
Ambulatory Surgical Center Payment System Final Rule. Technical Report CMS-1736FC, Centers for Medicare \& Medicaid Services.

CMS (2020b). National Health Expenditures 2019 Highlights. Technical report, Centers for Medicare \& Medicaid Services.

Cutler, D. M., R. S. Huckman, and J. T. Kolstad (2010). Input Constraints and the Efficiency of Entry: Lessons from Cardiac Surgery. American Economic Journal: Economic Policy 2(1), 51-76.

Dranove, D., M. Shanley, and C. Simon (1992). Is Hospital Competition Wasteful? The RAND Journal of Economics 23(2), 247.

FDA (2000). FDA Approves New Robotic Surgery Device.

Finkelstein, J., E. Eckersberger, H. Sadri, S. Taneja, H. Lepor, and B. Djavan (2010). Open Versus Laparoscopic Versus Robot-Assisted Laparoscopic Prostatectomy: The European and US Experience. Reviews in Urology 12, 35-43.

Gourieroux, C., A. Monfort, and A. Trognon (1984, May). Pseudo Maximum Likelihood Methods: Applications to Poisson Models. Econometrica 52(3), 701.

Grossman, J. M. and D. A. Banks (1998). Unrestricted Entry and Nonprice Competition: The Case of Technological Adoption in Hospitals. International Journal of the Economics of Business 5(2), 223-245.

Gruber, J., P. Levine, and D. Staiger (1999, February). Abortion Legalization and Child Living Circumstances: Who is the "Marginal Child"? The Quarterly Journal of Economics 114(1), 263-291.

Hausman, J., B. H. Hall, and Z. Griliches (1984, July). Econometric Models for Count Data with an Application to the Patents-R \& D Relationship. Econometrica 52(4), 909. 
Hodgkin, D. (1996). Specialized service offerings and patients' choice of hospital: The case of cardiac catheterization. Journal of Health Economics 15(3), 305-332.

Hopkins, J. (2021). Transurethral Resection of the Prostate (TURP).

Ilic, D., S. M. Evans, C. A. Allan, J. H. Jung, D. Murphy, and M. Frydenberg (2017). Laparoscopic and robotic-assisted versus open radical prostatectomy for the treatment of localised prostate cancer. Cochrane Database of Systematic Reviews.

Jacobs, B. L., Y. Zhang, T. A. Skolarus, J. T. Wei, J. E. Montie, F. R. Schroeck, and B. K. Hollenbeck (2013). Certificate of Need Legislation and the Dissemination of Robotic Surgery for Prostate Cancer. Journal of Urology 189(1), 80-85.

Jorgenson, D. W. (2011). Innovation and Productivity Growth: T.W. Schultz Lecture. American Journal of Agricultural Economics 93(2), 276-296.

Kessler, D. P. and M. B. McClellan (2000). Is Hospital Competition Socially Wasteful? The Quarterly Journal of Economics 115(2), 577-615.

Ko, H. and S. A. Glied (2021, March). Robotic Prostatectomy and Prostate Cancer-Related Medicaid Spending: Evidence from New York State. Journal of General Internal Medicine.

Lepor, H. (2000). Selecting candidates for radical prostatectomy. Reviews in Urology 2(3), $182-189$.

Mack, M. J. (2001). Minimally Invasive and Robotic Surgery. JAMA 285(5), 568.

Mankiw, N. G. and M. D. Whinston (1986). Free Entry and Social Inefficiency. The RAND Journal of Economics 17(1), 48.

Sandoval Salinas, C., A. L. González Rangel, J. G. Cataño Cataño, J. C. Fuentes Pachón, and J. S. Castillo Londoño (2013, November). Efficacy of Robotic-Assisted Prostatectomy in Localized Prostate Cancer: A Systematic Review of Clinical Trials. Advances in Urology 2013, e105651. Publisher: Hindawi. 
Savage, C. J. and A. J. Vickers (2009). Low Annual Caseloads of United States Surgeons Conducting Radical Prostatectomy. Journal of Urology 182(6), 2677-2681.

Schwartz, L. M. and S. Woloshin (2019). Medical Marketing in the United States, 1997-2016. JAMA 321(1), 80.

SEC (2003). Intuitive Surgical and Computer Motion Announce Merger Agreement. Technical report, Securities and Exchange Commission.

Sheetz, K. H., J. Claflin, and J. B. Dimick (2020). Trends in the Adoption of Robotic Surgery for Common Surgical Procedures. JAMA Network Open 3(1), e1918911.

Skinner, J. (2011). Causes and Consequences of Regional Variations in Health Care. In Handbook of Health Economics, Volume 2, pp. 45-93. Elsevier.

Skinner, J. and D. Staiger (2007). Technology Adoption from Hybrid Corn to Beta-Blockers. In Hard-to-Measure Goods and Services: Essays in Honor of Zvi Griliches, pp. 545-570. University of Chicago Press.

Skinner, J. and D. Staiger (2015). Technology Diffusion and Productivity Growth in Health Care. Review of Economics and Statistics 97(5), 951-964.

USPSTF (2008). Screening for prostate cancer: U.S. Preventive Services Task Force recommendation statement. Annals of Internal Medicine 149, 185-191.

Wooldridge, J. M. (1999, May). Distribution-free estimation of some nonlinear panel data models. Journal of Econometrics 90(1), 77-97.

Yaxley, J. W., G. D. Coughlin, S. K. Chambers, S. Occhipinti, H. Samaratunga, L. Zajdlewicz, N. Dunglison, R. Carter, S. Williams, D. J. Payton, J. Perry-Keene, M. F. Lavin, and R. A. Gardiner (2016). Robot-assisted laparoscopic prostatectomy versus open radical retropubic prostatectomy: early outcomes from a randomised controlled phase 3 study. The Lancet 388(10049), 1057-1066. 


\section{Figures}

Figure 1: Robotic Adoption Over Time

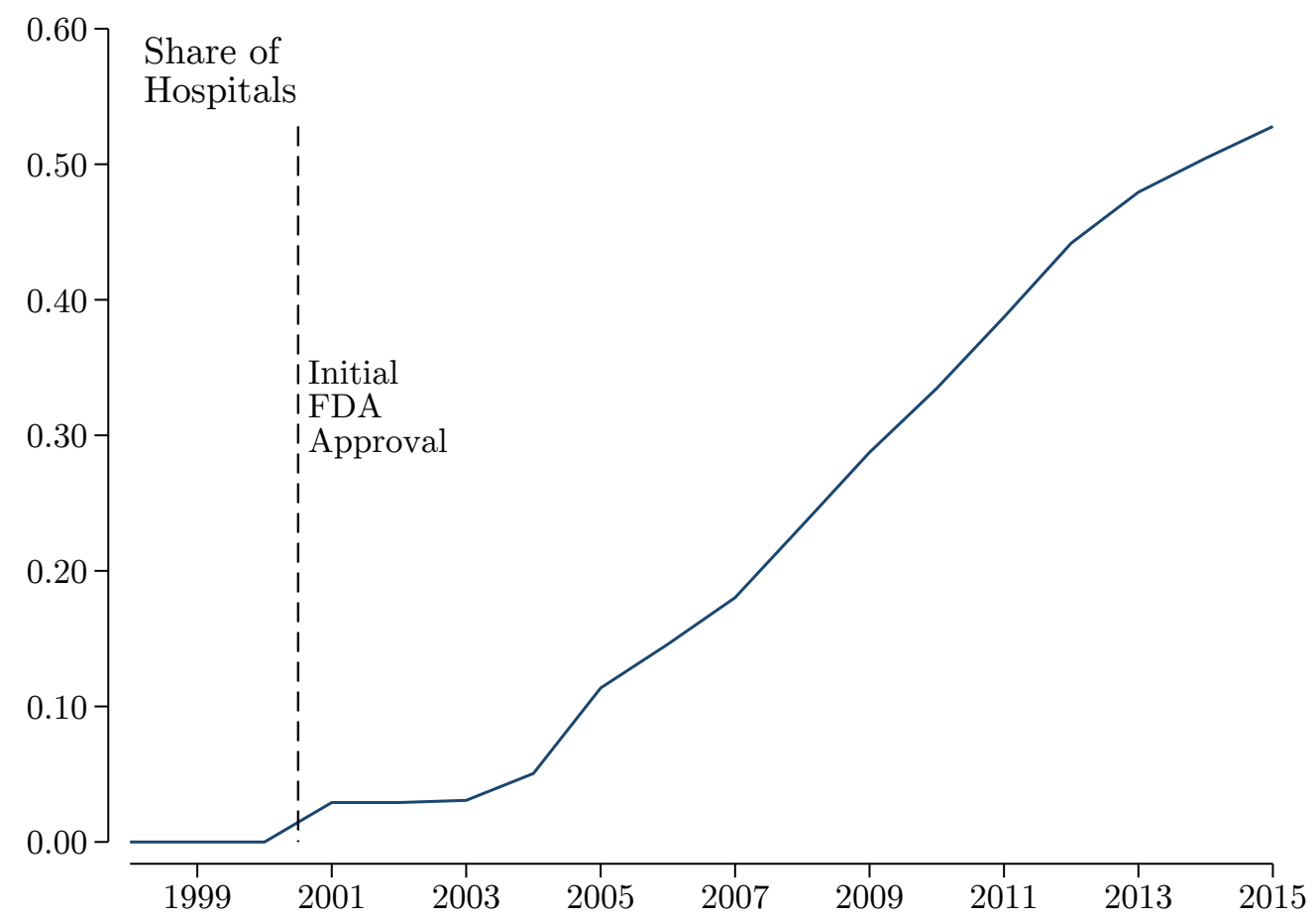

Notes: This figure shows the share of U.S. hospitals adopting a surgical robot according to data from the Intuitive Surgical Website (2001-2005) and the AHA survey (20052015). Adoption assumed to be $0 \%$ in 2000 , the year in which surgical robots were first approved for use in the U.S. 
Figure 2: Use of Robotic Surgery for Prostatectomies Over Time

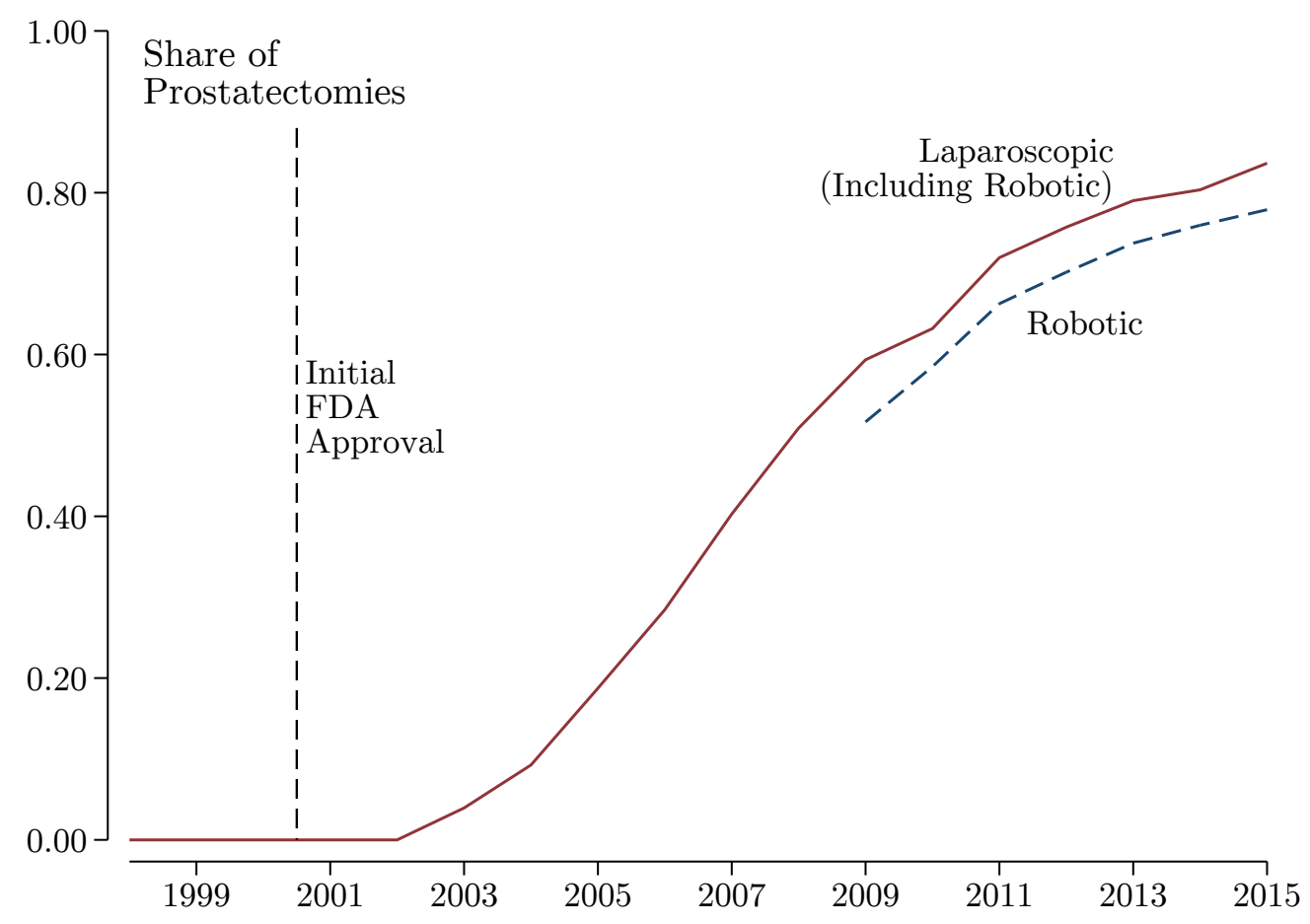

Notes: This figure depicts the share of prostatectomies conducted using surgical robots from 1998 to 2015 . The blue dashed line plots the robotic share, defined as the share of prostatectomies with a robot-assisted procedure code (it begins in 2009 because the robot-assist hospital procedure code was only created in late 2008). The red solid line plots the laparoscopic share for the full period, which we can observe well throughout by linking to physician procedural billing. In this series, the denominator is the subset of prostatectomy hospitalizations for which there was concurrent physician billing for any prostatectomy procedure during the stay (patient admission through discharge) while the numerator is further restricted to those with physician billing for a laparoscopic prostatectomy procedure. All procedure codes are listed in Appendix Table A1. Essentially all robotic prostatectomies are laparoscopic and the vast majority of laparoscopic prostatectomies use a robot. 
Figure 3: Event Studies of Patient Allocation

\section{a. Prostate Cancer}

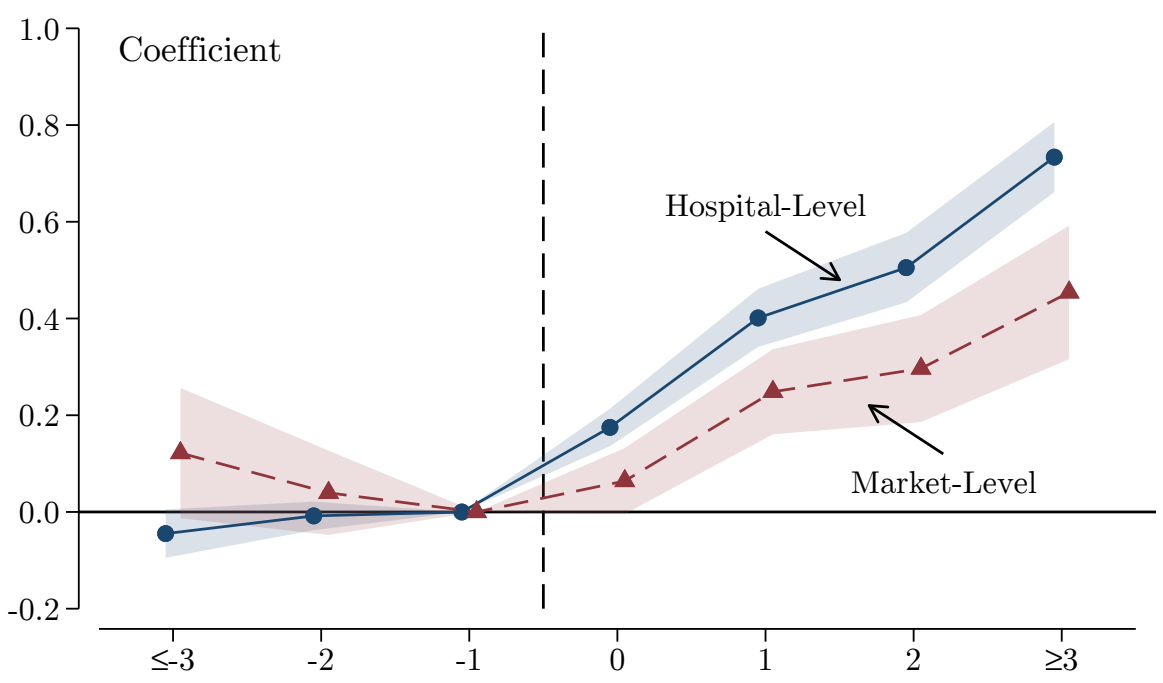

b. Prostatectomy

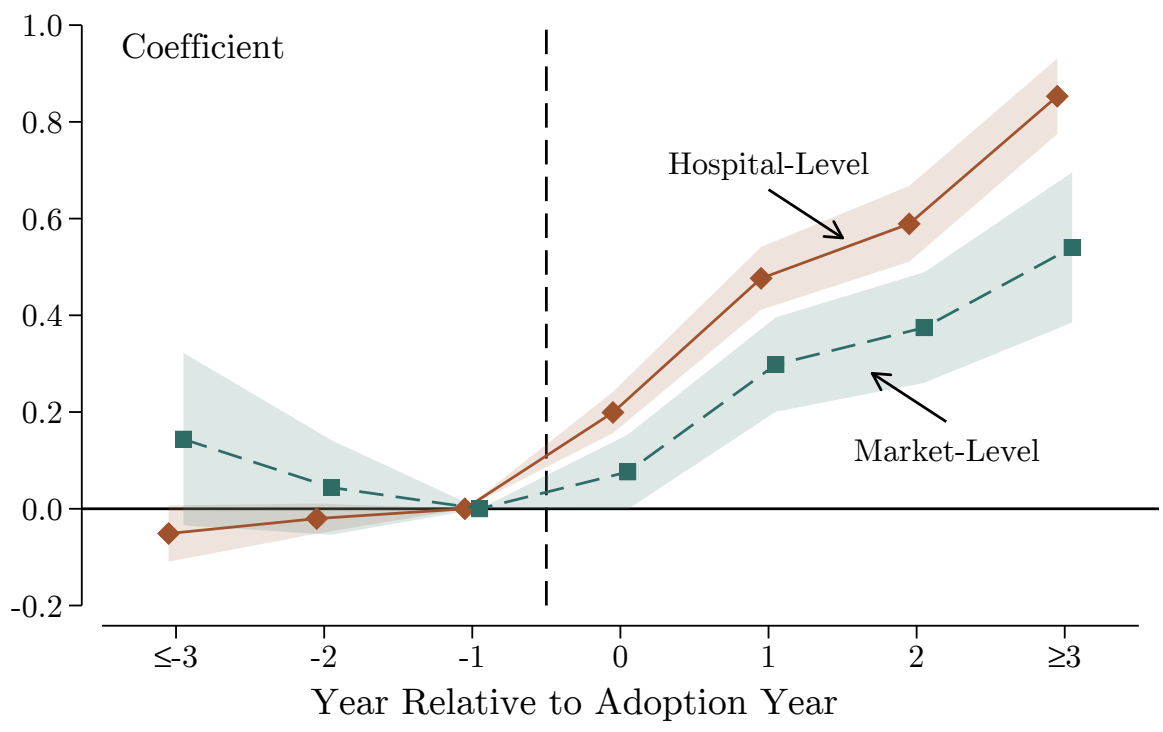

Notes: This figure plots event study coefficients from estimating equation 2 and its market-level analog. The outcome is prostate cancer patients in Panel A and prostatectomy patients in Panel B. The year prior to adoption is the reference year. The outcome is the volume of prostate cancer patients. Coefficients have a log-point interpretation, e.g. a coefficient of 0.2 implies a 20 log point change. Shaded areas depict 95\% confidence intervals based on robust standard errors clustered at the market level. Regressions control for year and level (hospital or market) fixed effects. 
Figure 4: Effect on Prostatectomy Volume by Patient Age and Chronic Conditions

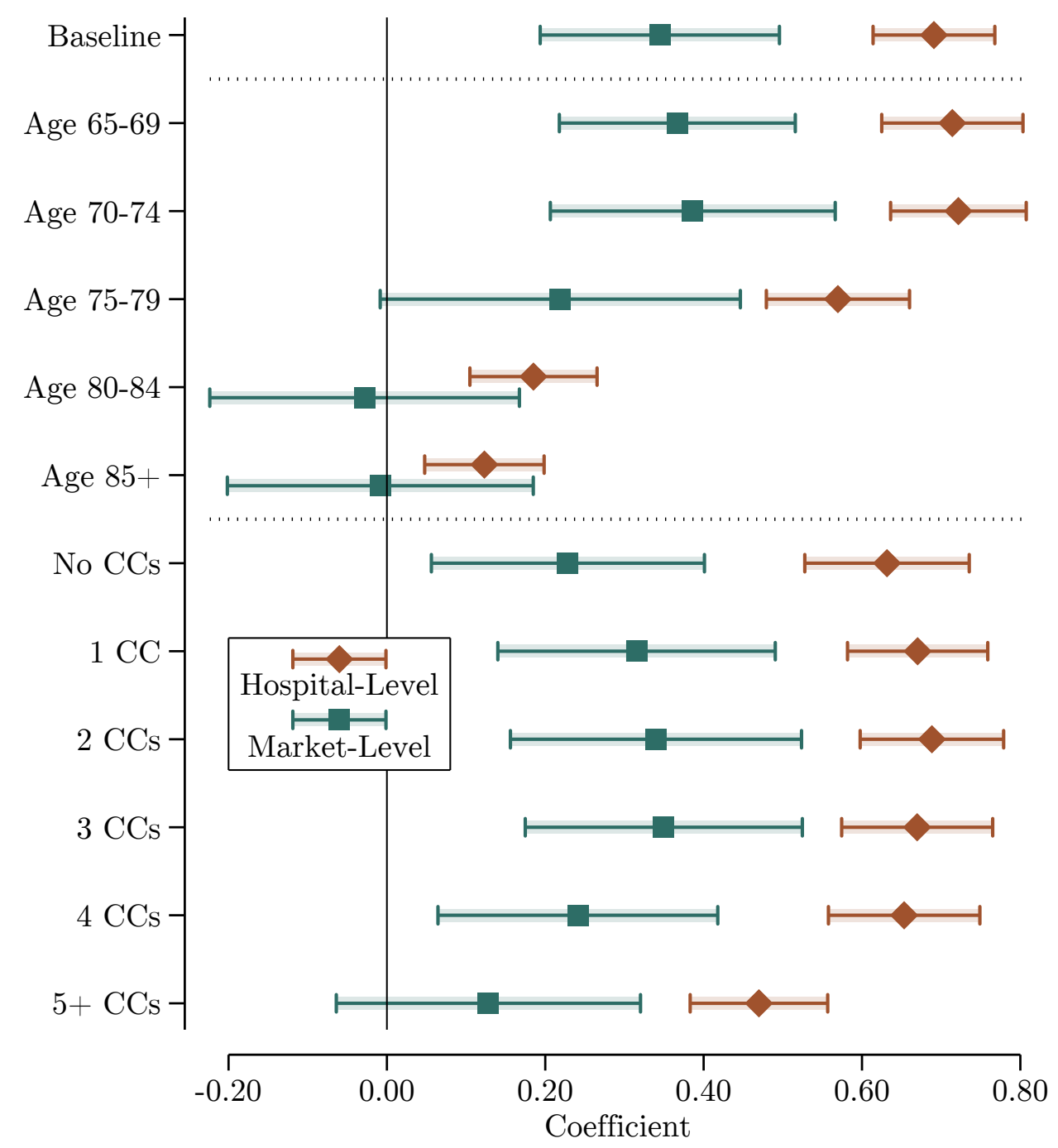

Notes: This figure plots estimates from equation 1 of the effect of adopting a robot on the volume of prostatectomy patients in the specified age and chronic condition (CC) bins. Hospital-level effects depicted with diamonds and market-level effects depicted with squares. Estimates of effects on the total volume of patients reported at the top of the figure ("Baseline", repeated from Table 2). Coefficients have a log-point interpretation, e.g. a coefficient of 0.2 implies a 20 log point change. Error bars depict 95\% confidence intervals based on robust standard errors clustered at the market level. Regressions control for year and level (hospital or market) fixed effects. 


\section{Tables}

Table 1: Summary Statistics for Hospitals in Sample

\begin{tabular}{|c|c|c|}
\hline & $\begin{array}{c}(1) \\
\text { Non-Adopters }\end{array}$ & $\begin{array}{c}(2) \\
\text { Adopters }\end{array}$ \\
\hline Beds & $\begin{array}{c}186.4 \\
(139.1)\end{array}$ & $\begin{array}{c}413.7 \\
(272.6)\end{array}$ \\
\hline Urban & $\begin{array}{c}0.61 \\
(0.49)\end{array}$ & $\begin{array}{c}0.94 \\
(0.24)\end{array}$ \\
\hline Teaching Hospital & $\begin{array}{c}0.13 \\
(0.34)\end{array}$ & $\begin{array}{c}0.32 \\
(0.47)\end{array}$ \\
\hline \multicolumn{3}{|l|}{ Patients (Annual) } \\
\hline Cancer (ex. skin) & $\begin{array}{c}87.2 \\
(77.9)\end{array}$ & $\begin{array}{c}324.9 \\
(308.9)\end{array}$ \\
\hline Prostate Cancer & $\begin{array}{c}4.5 \\
(6.4)\end{array}$ & $\begin{array}{c}18.9 \\
(23.3)\end{array}$ \\
\hline Prostatectomy & $\begin{array}{c}3.3 \\
(5.2)\end{array}$ & $\begin{array}{c}15.7 \\
(21.0)\end{array}$ \\
\hline \multicolumn{3}{|l|}{ Market Share } \\
\hline Prostate Cancer & $\begin{array}{c}0.06 \\
(0.12)\end{array}$ & $\begin{array}{c}0.20 \\
(0.23)\end{array}$ \\
\hline Prostatectomy & $\begin{array}{c}0.05 \\
(0.12)\end{array}$ & $\begin{array}{c}0.20 \\
(0.24)\end{array}$ \\
\hline $\begin{array}{l}\text { Hospitals } \\
\text { Observations }\end{array}$ & $\begin{array}{c}1,168 \\
21,024\end{array}$ & $\begin{array}{c}1,093 \\
19,674\end{array}$ \\
\hline
\end{tabular}

Notes: This table shows summary statistics for the sample of hospitals included in the main hospital-level analyses. See text for more information on sample construction. All characteristics are at the hospital-year level spanning 1998-2015. Market share defined as the hospital's patient count divided by the patient count in its market. Standard deviations presented in parentheses. 
Table 2: Estimates of Effect of Adoption on Patient Volume

\begin{tabular}{|c|c|c|c|c|}
\hline \multirow[b]{3}{*}{ Patients: } & $(1)$ & $(2)$ & (3) & (4) \\
\hline & \multicolumn{2}{|c|}{ Hospital-Level } & \multicolumn{2}{|c|}{ Market-Level } \\
\hline & Prostate Cancer & Prostatectomy & Prostate Cancer & Prostatectomy \\
\hline \multirow[t]{2}{*}{ Interim } & 0.17 & 0.19 & -0.04 & -0.05 \\
\hline & $(0.03)$ & $(0.03)$ & $(0.06)$ & $(0.07)$ \\
\hline \multirow[t]{2}{*}{ Post } & 0.59 & 0.69 & 0.28 & 0.34 \\
\hline & $(0.04)$ & $(0.04)$ & $(0.07)$ & $(0.08)$ \\
\hline \multirow[t]{2}{*}{ Marginal Effect } & 7.8 & 7.6 & 27.8 & 27.8 \\
\hline & $(0.5)$ & $(0.5)$ & $(7.8)$ & $(6.8)$ \\
\hline DV Average & 11.5 & 9.5 & 90.2 & 73.1 \\
\hline Hospitals/Markets & 2,255 & 2,212 & 306 & 306 \\
\hline Observations & 40,590 & 39,816 & 5,508 & 5,508 \\
\hline
\end{tabular}

Notes: This table depicts the results of estimating equation 1 (columns 1 and 2) and its market-level analog (columns 3 and 4). The dependent variable is prostate cancer patient volume (columns 1 and 3) and prostatectomy patient volume (columns 2 and 4). Interim indicates the first year the hospital reports having a robot while Post indicates the subsequent years. Coefficients have a logpoint interpretation, e.g. a coefficient of 0.2 implies a $20 \mathrm{log}$ point change. Marginal effect is the expected absolute change in patient volume derived from the Post coefficient. DV average is the average dependent variable (patient volume) in the regression. Robust standard errors clustered at the market level in parentheses. Regressions control for year and level (hospital or market) fixed effects. 
Table 3: Effect of Adoption on Characteristics of Prostatectomy Patients

\begin{tabular}{|c|c|c|c|c|c|c|c|}
\hline \multirow[b]{2}{*}{ Characteristic: } & \multicolumn{2}{|c|}{ Hospital-Level } & \multicolumn{5}{|c|}{ Market-Level } \\
\hline & $\begin{array}{l}(1) \\
\text { Age } \\
\end{array}$ & $\begin{array}{c}\text { (2) } \\
\text { Chronic } \\
\text { Conditions }\end{array}$ & (3) & $\begin{array}{c}(4) \\
\text { Chronic } \\
\text { Conditions }\end{array}$ & $\begin{array}{c}(5) \\
\text { Beds } \\
\text { (Baseline) } \\
\end{array}$ & $\begin{array}{c}(6) \\
\text { Volume } \\
\text { (Baseline) }\end{array}$ & $\begin{array}{c}\quad(7) \\
\text { Teaching } \\
\text { Hospital }\end{array}$ \\
\hline $\begin{array}{l}\text { A. First Stage: Outcom } \\
\text { Post }\end{array}$ & $\begin{array}{c}\text { e is Pati } \\
0.542 \\
(0.035)\end{array}$ & $\begin{array}{l}\text { nt Volume } \\
0.490 \\
(0.040)\end{array}$ & $\begin{array}{c}0.342 \\
(0.077)\end{array}$ & $\begin{array}{c}0.260 \\
(0.082)\end{array}$ & $\begin{array}{c}0.342 \\
(0.077)\end{array}$ & $\begin{array}{c}0.342 \\
(0.077)\end{array}$ & $\begin{array}{c}0.342 \\
(0.077)\end{array}$ \\
\hline $\begin{array}{l}\text { B. Reduced Form: Outc } \\
\text { Post }\end{array}$ & $\begin{array}{c}\text { ome is } A \\
-0.029 \\
(0.002)\end{array}$ & $\begin{array}{c}\text { erage Chara } \\
-0.136 \\
(0.015)\end{array}$ & $\begin{array}{l}\text { teristic } \\
-0.023 \\
(0.005)\end{array}$ & $\begin{array}{l}-0.064 \\
(0.034)\end{array}$ & $\begin{array}{c}0.021 \\
(0.025)\end{array}$ & $\begin{array}{c}0.037 \\
(0.029)\end{array}$ & $\begin{array}{c}0.084 \\
(0.065)\end{array}$ \\
\hline $\begin{array}{l}\text { C. Ratio of Reduced Fo } \\
\text { Elasticity }\end{array}$ & $\begin{array}{l}m \text { to Fir } \\
-0.054 \\
(0.004)\end{array}$ & $\begin{array}{c}\text { Stage: Ela } \\
-0.277 \\
(0.033)\end{array}$ & $\begin{array}{l}\text { ticity of } \\
-0.067 \\
(0.020)\end{array}$ & $\begin{array}{c}\text { Average Ch } \\
\quad-0.248 \\
(0.149)\end{array}$ & $\begin{array}{l}\text { racteristic } \\
0.061 \\
(0.075)\end{array}$ & $\begin{array}{c}\text { ith Respect } \\
0.107 \\
(0.088)\end{array}$ & $\begin{array}{l}\text { Volume } \\
\qquad 0.245 \\
(0.191)\end{array}$ \\
\hline $\begin{array}{l}\text { Average Characteristic } \\
\text { Hospitals/Markets } \\
\text { Observations }\end{array}$ & $\begin{array}{c}73.32 \\
2,191 \\
62,046\end{array}$ & $\begin{array}{c}2.68 \\
2,164 \\
53,808\end{array}$ & $\begin{array}{c}72.24 \\
306 \\
10,956\end{array}$ & $\begin{array}{c}2.50 \\
306 \\
9,732\end{array}$ & $\begin{array}{c}413.08 \\
306 \\
10,956\end{array}$ & $\begin{array}{c}22.02 \\
306 \\
10,942\end{array}$ & $\begin{array}{c}0.46 \\
306 \\
8,925\end{array}$ \\
\hline
\end{tabular}

Notes: This table reports results from estimating the impact of robotic adoption on the characteristics of prostatectomy patients. Panel A reports the "first stage" results from estimating equation 1 and differs only from Table 2 because it omits observations (hospital- or market-years) with no prostatectomy patients. Panel B reports the "reduced form" estimates of the same specification with the outcome redefined as the average characteristic of prostatectomy patients. Coefficients in Panels $\mathrm{A}$ and $\mathrm{B}$ have a log-point interpretation, e.g. a coefficient of 0.2 implies a 20 log point change in volume or the average characteristic. Panel $\mathrm{C}$ reports the ratio of the reduced form estimate to the first stage estimate. These coefficients have an elasticity interpretation, i.e. the elasticity of the average characteristic with respect to volume. In columns 5-7, the outcome is the average characteristic of the patients' hospitals. Columns 5 and 6 measure the hospital's beds and prostatectomy patient volume at baseline (1998) levels. See text for more details. Robust standard errors clustered at the market level in parentheses. Regressions control for year and level (hospital or market) fixed effects. 


\section{Appendix To:}

\section{Technology Adoption and Market Allocation: \\ The Case of Robotic Surgery}

Danea Horn, Adam Sacarny, Annetta Zhou

September 17, 2021 


\section{A Estimating Effects of Adoption on the Characteristics of the Average and Marginal Patient}

In Section 5.3 of the main text, we estimate the effect of robot adoption on the average characteristics of patients as well as the characteristics of the marginal patients induced to receive treatment. To develop this approach, we draw on Gruber et al. (1999) and construct the Poisson regression analog to their two-stage least squares approach. Here, the "first stage" repeats our main specification given by equation 1, which we use to estimate the effect of adoption on patient volume in the text:

$$
N_{h t}=\exp \left(\alpha_{t}+\alpha_{h}+\beta \cdot \text { interim }_{h t}+\gamma \cdot \text { post }_{h t}+X_{h t} \Omega\right)+\epsilon_{h t} .
$$

We also estimate a "reduced form" effect of robot adoption on the average characteristics of patients in the hospital (or market):

$$
C_{h t}=\exp \left(\delta_{t}+\delta_{h}+\kappa \cdot \text { interim }_{h t}+\lambda \cdot \text { post }_{h t}+X_{h t} \Phi\right)+v_{h t}
$$

where $C_{h t}$ is the average characteristic of patients treated at hospital $h$ in year $t .12$ In the Poisson model, $\gamma$ can be interpreted as the log-point effect of adoption on patient volume while $\lambda$ represents the log point effect of adoption on the average patient characteristic.

These estimates can be combined to yield an elasticity of average patient characteristics with respect to volume:

$$
\eta=\frac{\lambda}{\gamma}
$$

\footnotetext{
${ }^{12}$ This average is not defined for a hospital (or market) with no patients in the given year. Hence, observations with no patients must drop out from this regression. To ensure both regressions are run with the same sample, we omit any hospital-year or market-year with no patients from both.
} 
Assuming there are no defiers - people who only come to the hospital if there is no robot, and do not come if there is one - this elasticity can also be interpreted as the log-point difference in average characteristics between the marginal patients and incumbent patients. We conduct inference on this object by estimating the "first stage" and "reduced form" as a stacked regression, an approach that is analogous to seemingly unrelated regression and is supported by the Stata command ppmlhdfe, and using the delta method. The market estimates follow the same methodology with a change in notation from $h$ indexing hospitals to $r$ indexing markets. 


\section{Appendix Figures}

Figure A1: Trends in Prostate Cancer and Prostatectomy Hospitalizations, 1998 - 2015

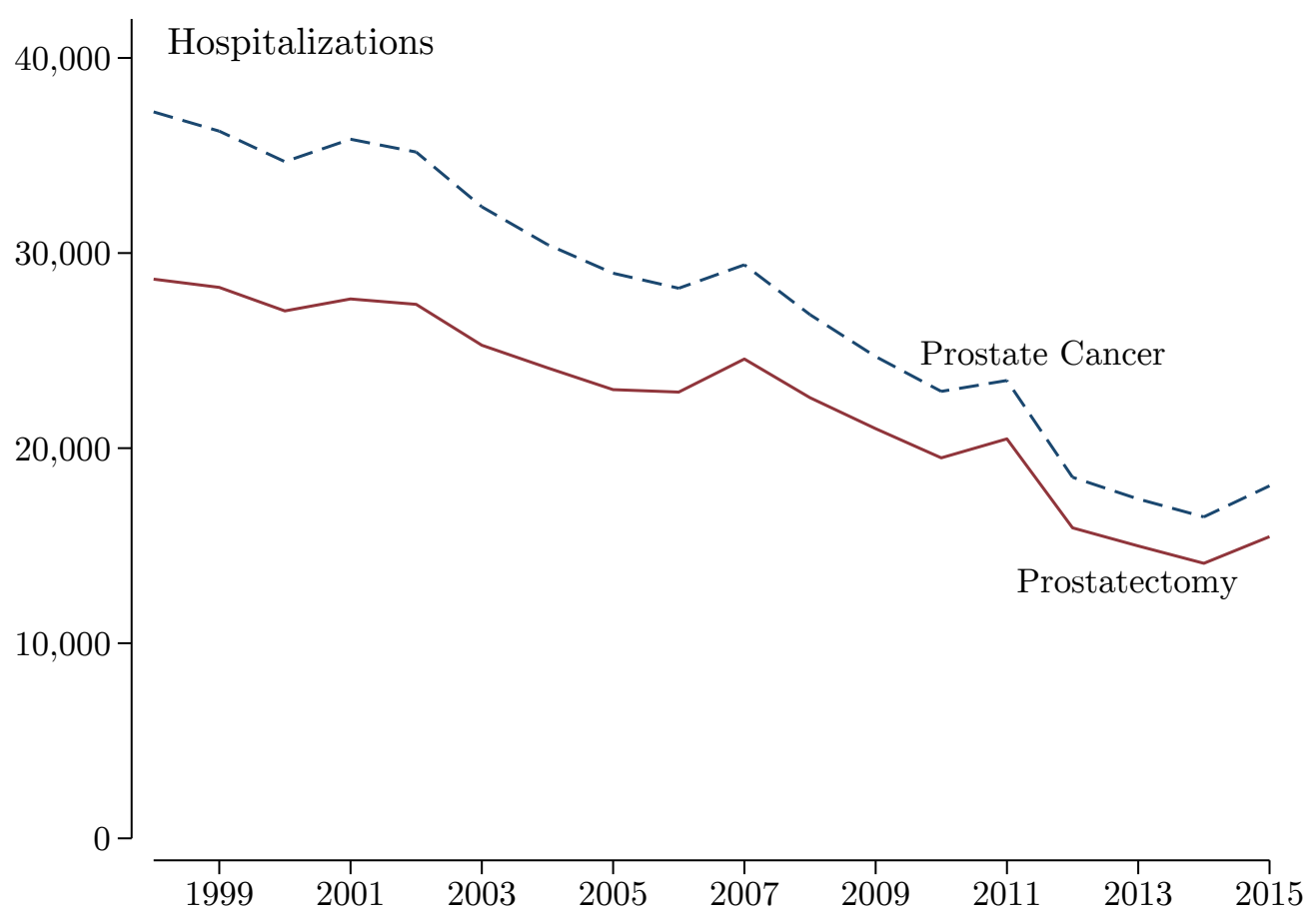

Notes: This figure shows the total number of Original Medicare hospitalizations for prostate cancer and prostatectomy from 1998 - 2015. 
Figure A2: Effect on Prostate Cancer Volume by Patient Age and Chronic Conditions

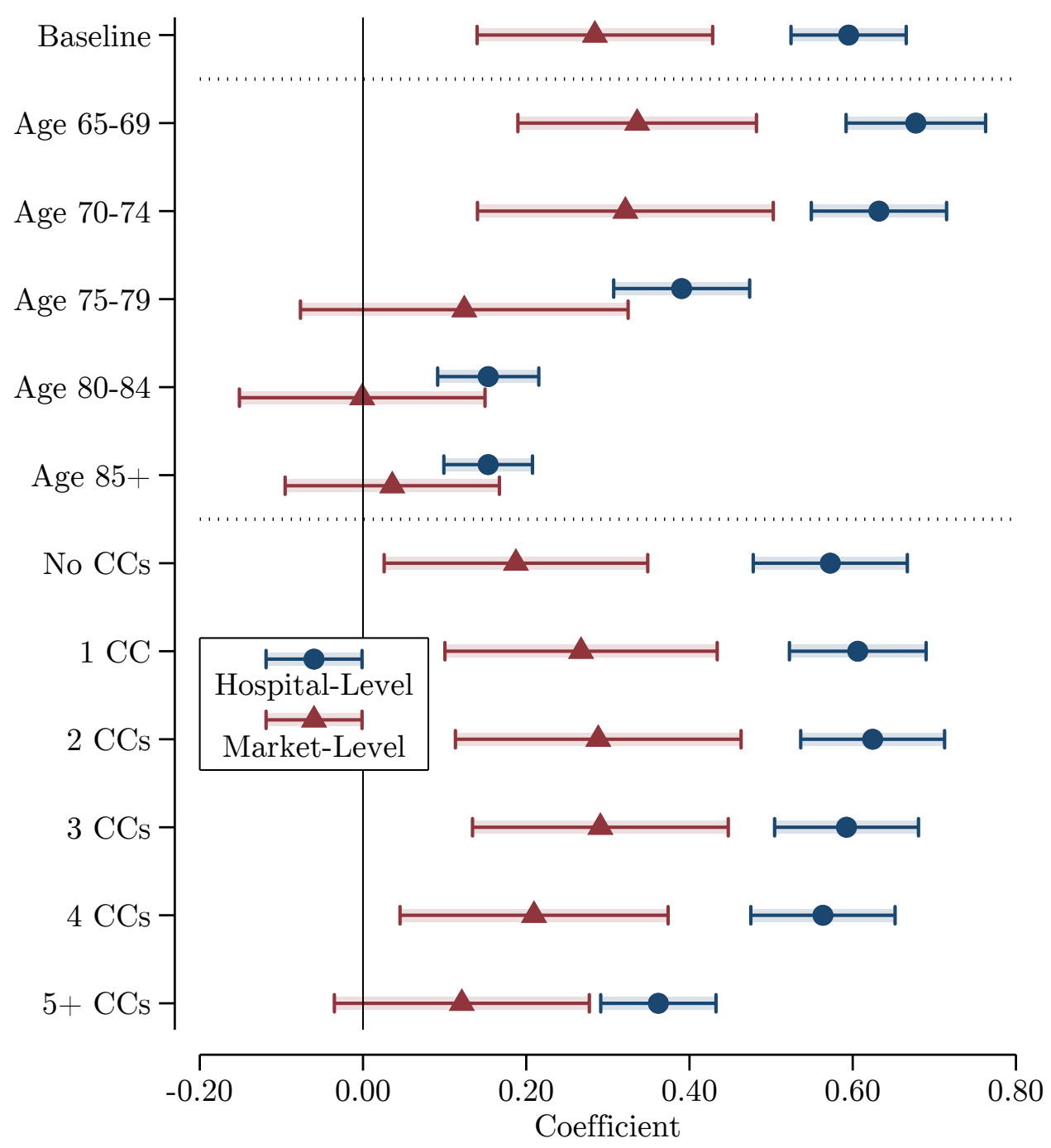

Notes: This figure plots estimates from equation 1 of the effect of adopting a robot on the volume of prostate cancer patients in the specified age and chronic condition (CC) bins. Hospital-level effects depicted with circles and market-level effects depicted with triangles. Estimates of effects on the total volume of patients reported at the top of the figure ("Baseline", repeated from Table 2). Coefficients have a log-point interpretation, e.g. a coefficient of 0.2 implies a $20 \log$ point change. Error bars depict $95 \%$ confidence intervals based on robust standard errors clustered at the market level. Regressions control for year and level (hospital or market) fixed effects. 


\section{Appendix Tables}

Table A1: Diagnosis and Procedure Codes Used to Identify Relevant Patients

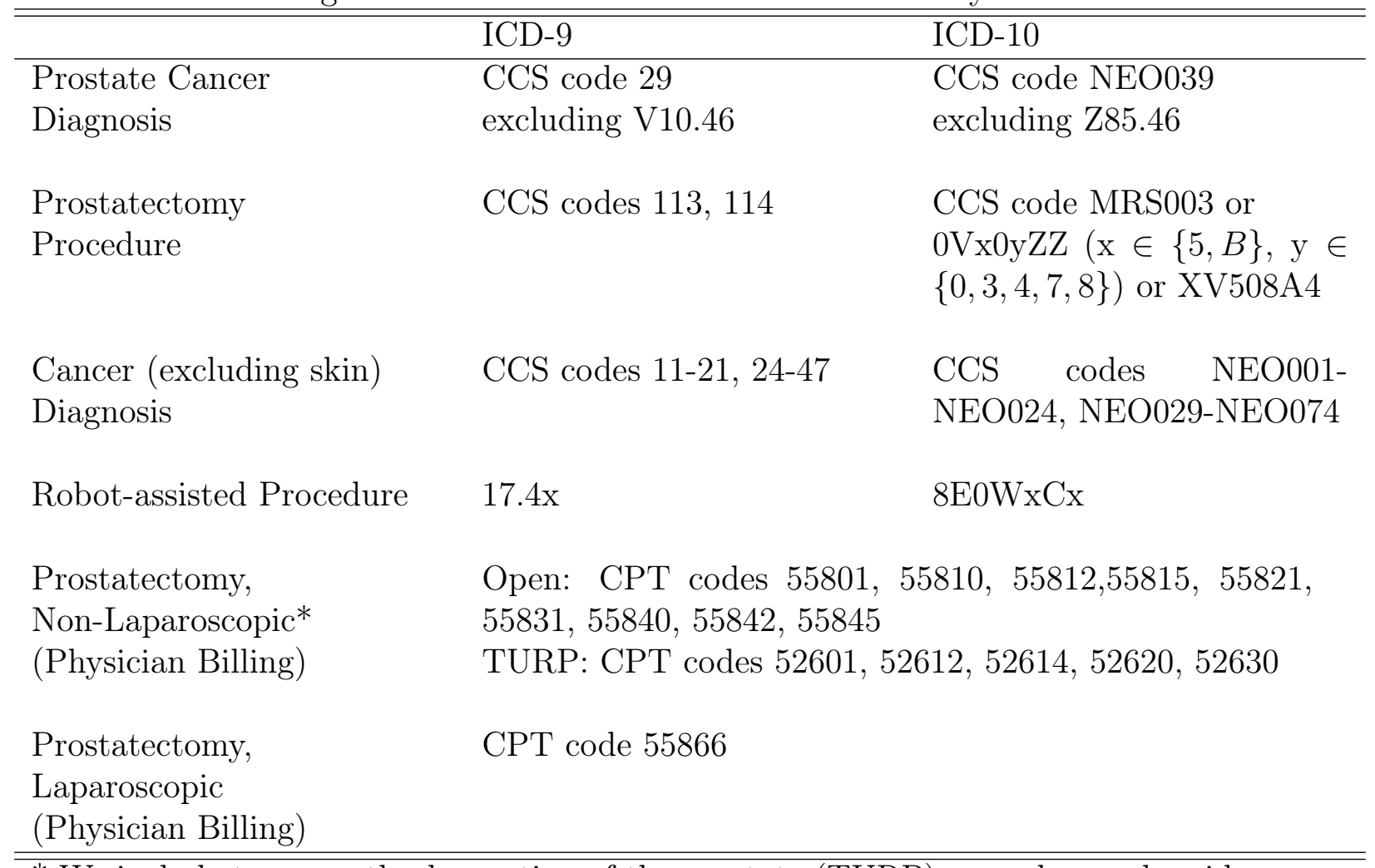

* We include trans-urethral resection of the prostate (TURP) procedures when identifying prostatectomies in physician billing. 
Table A2: Robustness of Prostate Cancer Hospital-Level Results

\begin{tabular}{|c|c|c|c|c|c|c|c|c|c|c|c|}
\hline & \multirow[b]{2}{*}{ (1) } & \multicolumn{4}{|c|}{ Controls } & \multicolumn{2}{|c|}{ Sample } & \multicolumn{2}{|c|}{ Model } & \multicolumn{2}{|c|}{ Dynamics } \\
\hline & & $(2)$ & $(3)$ & $(4)$ & $(5)$ & $(6)$ & (7) & $(8)$ & (9) & $(10)$ & (11) \\
\hline & & Fixed & Bed-Year & Market-Year & Market & Ever & All & Log- & asinh- & & Ever \\
\hline & Baseline & Trends & FE & FE & Adoption & Adopters & Hospitals & Linear & Linear & Baseline & Adopters \\
\hline Interim & 0.17 & 0.10 & 0.17 & 0.22 & 0.17 & 0.05 & 0.17 & 0.17 & 0.22 & 0.27 & 0.20 \\
\hline & $(0.03)$ & $(0.02)$ & $(0.03)$ & $(0.03)$ & $(0.03)$ & $(0.03)$ & $(0.03)$ & $(0.02)$ & $(0.02)$ & $(0.02)$ & $(0.02)$ \\
\hline Post & 0.59 & 0.36 & 0.57 & 0.72 & 0.59 & 0.37 & 0.62 & 0.49 & 0.62 & 0.53 & 0.44 \\
\hline & $(0.04)$ & $(0.04)$ & $(0.04)$ & $(0.03)$ & $(0.04)$ & $(0.04)$ & $(0.03)$ & $(0.03)$ & $(0.03)$ & $(0.04)$ & $(0.04)$ \\
\hline Interim (Rest of Market) & & & & & -0.08 & & & & & & \\
\hline & & & & & $(0.07)$ & & & & & & \\
\hline Post (Rest of Market) & & & & & -0.19 & & & & & & \\
\hline & & & & & $(0.09)$ & & & & & & \\
\hline Post $*$ & & & & & & & & & & 0.09 & 0.08 \\
\hline Relative Adopt Year & & & & & & & & & & $(0.01)$ & $(0.01)$ \\
\hline DV Average & 11.5 & 11.5 & 11.5 & 11.5 & 11.5 & 19.0 & 9.5 & 1.8 & 2.3 & 11.5 & 19.0 \\
\hline Hospitals & 2,255 & 2,255 & 2,255 & 2,236 & 2,255 & 1,090 & 2,929 & 2,261 & 2,261 & 2,255 & 1,090 \\
\hline Observations & 40,590 & 40,590 & 40,590 & 40,225 & 40,590 & 19,620 & 52,722 & 40,698 & 40,698 & 40,590 & 19,620 \\
\hline
\end{tabular}

Notes: This table assess the robustness of the hospital-level results on prostate cancer patient volume. Column (1) repeats the baseline estimate from Table 2 .

Columns 2-5 add controls for hospital-specific linear trends, hospital bed size decile indicators interacted with years, market-year fixed effects, and rest-of-market robot adoption, respectively. Column 6 limits the sample to hospitals that adopted a robot, dropping never-adopters. Column 7 expands the sample to all hospitals that treated at least 1 patient annually during the analysis period, adding back hospitals that adopted a robot after 2012 or that failed to meet the minimum patient thresholds described in the main text. Columns 8 and 9 use linear regression instead of Poisson regression with the outcomes defined as $\ln \left(N_{h t}+1\right)$ and asinh $\left(N_{h t}\right)$, respectively. Columns 10 and 11 add an interaction between Post and the hospital's relative adoption year (which starts at zero in the first year the hospital's Post indicator turns on) to the models previously estimated in columns 1 and 6 , respectively. See text for more details. Robust standard errors clustered at the market level in parentheses. All regressions control for year and hospital fixed effects. 
Table A3: Robustness of Prostatectomy Hospital-Level Results

\begin{tabular}{|c|c|c|c|c|c|c|c|c|c|c|c|}
\hline & \multirow[b]{2}{*}{$(1)$} & \multicolumn{4}{|c|}{ Controls } & \multicolumn{2}{|c|}{ Sample } & \multicolumn{2}{|c|}{ Model } & \multicolumn{2}{|c|}{ Dynamics } \\
\hline & & $\begin{array}{c}\text { (2) } \\
\text { Fixed } \\
\text { Trends }\end{array}$ & $\begin{array}{c}(3) \\
\text { Bed-Year } \\
\text { FE }\end{array}$ & $\begin{array}{c}(4) \\
\text { Market-Year } \\
\text { FE }\end{array}$ & $\begin{array}{c}(5) \\
\text { Market } \\
\text { Adoption }\end{array}$ & $\begin{array}{c}\text { (6) } \\
\text { Ever } \\
\text { Adopters }\end{array}$ & $\begin{array}{c}\text { (7) } \\
\text { All } \\
\text { Hospitals }\end{array}$ & $\begin{array}{c}(8) \\
\text { Log- } \\
\text { Linear }\end{array}$ & $\begin{array}{c}(9) \\
\text { asinh- } \\
\text { Linear }\end{array}$ & $\begin{array}{c}\text { (10) } \\
\text { Baseline }\end{array}$ & $\begin{array}{c}\text { (11) } \\
\text { Ever } \\
\text { Adopters }\end{array}$ \\
\hline Interim & $\begin{array}{c}0.19 \\
(0.03)\end{array}$ & $\begin{array}{c}0.11 \\
(0.03)\end{array}$ & $\begin{array}{c}0.19 \\
(0.03)\end{array}$ & $\begin{array}{c}0.26 \\
(0.03)\end{array}$ & $\begin{array}{c}0.19 \\
(0.03)\end{array}$ & $\begin{array}{c}0.05 \\
(0.04)\end{array}$ & $\begin{array}{c}0.19 \\
(0.03)\end{array}$ & $\begin{array}{c}0.17 \\
(0.02)\end{array}$ & $\begin{array}{c}0.22 \\
(0.03)\end{array}$ & $\begin{array}{c}0.32 \\
(0.02)\end{array}$ & $\begin{array}{c}0.24 \\
(0.03)\end{array}$ \\
\hline Post & $\begin{array}{c}0.69 \\
(0.04)\end{array}$ & $\begin{array}{c}0.43 \\
(0.04)\end{array}$ & $\begin{array}{c}0.66 \\
(0.04)\end{array}$ & $\begin{array}{c}0.85 \\
(0.04)\end{array}$ & $\begin{array}{c}0.69 \\
(0.04)\end{array}$ & $\begin{array}{c}0.43 \\
(0.05)\end{array}$ & $\begin{array}{c}0.72 \\
(0.04)\end{array}$ & $\begin{array}{c}0.54 \\
(0.03)\end{array}$ & $\begin{array}{c}0.67 \\
(0.04)\end{array}$ & $\begin{array}{c}0.64 \\
(0.04)\end{array}$ & $\begin{array}{c}0.53 \\
(0.04)\end{array}$ \\
\hline Interim (Rest of Market) & & & & & $\begin{array}{l}-0.09 \\
(0.08)\end{array}$ & & & & & & \\
\hline Post (Rest of Market) & & & & & $\begin{array}{l}-0.20 \\
(0.10)\end{array}$ & & & & & & \\
\hline $\begin{array}{l}\text { Post }{ }^{*} \\
\quad \text { Relative Adopt Year }\end{array}$ & & & & & & & & & & $\begin{array}{c}0.11 \\
(0.01)\end{array}$ & $\begin{array}{c}0.09 \\
(0.01)\end{array}$ \\
\hline DV Average & 9.5 & 9.5 & 9.5 & 9.5 & 9.5 & 15.8 & 8.5 & 1.6 & 2.0 & 9.5 & 15.8 \\
\hline Hospitals & 2,212 & 2,212 & 2,212 & 2,190 & 2,212 & 1,090 & 2,669 & 2,261 & 2,261 & 2,212 & 1,090 \\
\hline Observations & 39,816 & 39,816 & 39,816 & 39,369 & 39,816 & 19,620 & 48,042 & 40,698 & 40,698 & 39,816 & 19,620 \\
\hline
\end{tabular}

Notes: This table assess the robustness of the hospital-level results on prostatectomy patient volume. Column (1) repeats the baseline estimate from Table 2 . Columns 2-5 add controls for hospital-specific linear trends, hospital bed size decile indicators interacted with years, market-year fixed effects, and rest-of-market robot adoption, respectively. Column 6 limits the sample to hospitals that adopted a robot, dropping never-adopters. Column 7 expands the sample to all hospitals that treated at least 1 patient annually during the analysis period, adding back hospitals that adopted a robot after 2012 or that failed to meet the minimum patient thresholds described in the main text. Columns 8 and 9 use linear regression instead of Poisson regression with the outcomes defined as $\ln \left(N_{h t}+1\right)$ and asinh $\left(N_{h t}\right)$, respectively. Columns 10 and 11 add an interaction between Post and the hospital's relative adoption year (which starts at zero in the first year the hospital's Post indicator turns on) to the models previously estimated in columns 1 and 6 , respectively. See text for more details. Robust standard errors clustered at the market level in parentheses. All regressions control for year and hospital fixed effects. 
Table A4: Robustness of Prostate Cancer Market-Level Results

\begin{tabular}{|c|c|c|c|c|c|}
\hline & \multirow{3}{*}{ (1) } & \multirow{3}{*}{$\begin{array}{c}\text { Controls } \\
(2) \\
\text { Fixed }\end{array}$} & \multirow{3}{*}{$\begin{array}{c}\text { Sample } \\
(3) \\
\text { Broad Hosp. }\end{array}$} & \multicolumn{2}{|c|}{ Model } \\
\hline & & & & (4) & $(5)$ \\
\hline & & & & Log- & asinh- \\
\hline & Baseline & Trends & Sample & Linear & Linear \\
\hline Interim & -0.04 & -0.00 & -0.04 & -0.03 & -0.05 \\
\hline & $(0.06)$ & $(0.05)$ & $(0.06)$ & $(0.06)$ & $(0.06)$ \\
\hline Post & 0.28 & 0.20 & 0.31 & 0.43 & 0.46 \\
\hline & $(0.07)$ & $(0.07)$ & $(0.08)$ & $(0.07)$ & $(0.08)$ \\
\hline DV Average & 90.2 & 90.2 & 91.3 & 4.0 & 4.7 \\
\hline Markets & 306 & 306 & 306 & 306 & 306 \\
\hline Observations & 5,508 & 5,508 & 5,508 & 5,508 & 5,508 \\
\hline
\end{tabular}

Notes: This table assess the robustness of the market-level results on prostate cancer patient volume. Column (1) repeats the baseline estimate from Table 2. Columns 2 adds controls for market-specific linear trends. Column 3 expands the sample of hospitals used to measure market-level adoption and patient volume to include hospitals that failed to meet the minimum patient thresholds described in the main text. Columns 4 and 5 use linear regression instead of Poisson regression with the outcomes defined as $\ln \left(N_{r t}+1\right)$ and $\operatorname{asinh}\left(N_{r t}\right)$, respectively. See text for more details. Robust standard errors clustered at the market level in parentheses. All regressions control for year and market fixed effects. 
Table A5: Robustness of Prostatectomy Market-Level Results

\begin{tabular}{|c|c|c|c|c|c|}
\hline & \multirow{3}{*}{ (1) } & Controls & Sample & \multicolumn{2}{|c|}{ Model } \\
\hline & & $(2)$ & $(3)$ & $(4)$ & $(5)$ \\
\hline & & Fixed & Broad Hosp. & Log- & asinh- \\
\hline & Baseline & Trends & Sample & Linear & Linear \\
\hline Interim & -0.05 & 0.02 & -0.04 & -0.01 & -0.03 \\
\hline & $(0.07)$ & $(0.04)$ & $(0.07)$ & $(0.06)$ & $(0.07)$ \\
\hline Post & 0.34 & 0.29 & 0.37 & 0.54 & 0.60 \\
\hline & $(0.08)$ & $(0.06)$ & $(0.08)$ & $(0.08)$ & $(0.09)$ \\
\hline DV Average & 73.1 & 73.1 & 73.8 & 3.8 & 4.4 \\
\hline Markets & 306 & 306 & 306 & 306 & 306 \\
\hline Observations & 5,508 & 5,508 & 5,508 & 5,508 & 5,508 \\
\hline
\end{tabular}

Notes: This table assess the robustness of the market-level results on prostatectomy patient volume. Column (1) repeats the baseline estimate from Table 2. Columns 2 adds controls for market-specific linear trends. Column 3 expands the sample of hospitals used to measure market-level adoption and patient volume to include hospitals that failed to meet the minimum patient thresholds described in the main text. Columns 4 and 5 use linear regression instead of Poisson regression with the outcomes defined as $\ln \left(N_{r t}+1\right)$ and $\operatorname{asinh}\left(N_{r t}\right)$, respectively. See text for more details. Robust standard errors clustered at the market level in parentheses. All regressions control for year and market fixed effects. 
Table A6: Effect of Adoption on Characteristics of Prostate Cancer Patients

\begin{tabular}{|c|c|c|c|c|c|c|c|}
\hline \multirow[b]{2}{*}{ Characteristic: } & \multicolumn{2}{|c|}{ Hospital-Level } & \multicolumn{5}{|c|}{ Market-Level } \\
\hline & $\begin{array}{l}\text { (1) } \\
\text { Age }\end{array}$ & $\begin{array}{c}\text { (2) } \\
\text { Chronic } \\
\text { Conditions }\end{array}$ & $\begin{array}{l}(3) \\
\text { Age } \\
\end{array}$ & $\begin{array}{c}(4) \\
\text { Chronic } \\
\text { Conditions }\end{array}$ & $\begin{array}{c}(5) \\
\text { Beds } \\
\text { (Baseline) } \\
\end{array}$ & $\begin{array}{c}(6) \\
\text { Volume } \\
\text { (Baseline) }\end{array}$ & $\begin{array}{c}\quad(7) \\
\text { Teaching } \\
\text { Hospital }\end{array}$ \\
\hline $\begin{array}{l}\text { A. First Stage: Outcom } \\
\text { Post }\end{array}$ & $\begin{array}{c}\text { e is Pati } \\
0.503 \\
(0.033)\end{array}$ & $\begin{array}{l}\text { nt Volume } \\
\quad 0.453 \\
(0.037)\end{array}$ & $\begin{array}{c}0.281 \\
(0.074)\end{array}$ & $\begin{array}{c}0.215 \\
(0.074)\end{array}$ & $\begin{array}{c}0.281 \\
(0.074)\end{array}$ & $\begin{array}{c}0.281 \\
(0.074)\end{array}$ & $\begin{array}{c}0.281 \\
(0.074)\end{array}$ \\
\hline $\begin{array}{l}\text { B. Reduced Form: Outc } \\
\text { Post }\end{array}$ & $\begin{array}{c}\text { ome is } A \\
-0.034 \\
(0.002)\end{array}$ & $\begin{array}{c}\text { erage Chara } \\
-0.128 \\
(0.013)\end{array}$ & $\begin{array}{l}\text { teristic } \\
-0.026 \\
(0.005)\end{array}$ & $\begin{array}{l}-0.071 \\
(0.029)\end{array}$ & $\begin{array}{c}0.019 \\
(0.020)\end{array}$ & $\begin{array}{c}0.016 \\
(0.022)\end{array}$ & $\begin{array}{c}0.054 \\
(0.050)\end{array}$ \\
\hline $\begin{array}{l}\text { C. Ratio of Reduced Fo } \\
\text { Elasticity }\end{array}$ & $\begin{array}{l}m \text { to Fir } \\
-0.068 \\
(0.005)\end{array}$ & $\begin{array}{c}\text { Stage: Ela } \\
-0.283 \\
(0.031)\end{array}$ & $\begin{array}{l}\text { ticity of } \\
-0.091 \\
(0.026)\end{array}$ & $\begin{array}{c}\text { Average } C h \\
\quad-0.332 \\
(0.169)\end{array}$ & $\begin{array}{l}\text { racteristic } \\
0.068 \\
(0.073)\end{array}$ & $\begin{array}{c}\text { ith Respect } \\
0.058 \\
(0.080)\end{array}$ & $\begin{array}{l}\text { Volume } \\
\qquad 0.192 \\
(0.180)\end{array}$ \\
\hline $\begin{array}{l}\text { Average Characteristic } \\
\text { Hospitals/Markets } \\
\text { Observations }\end{array}$ & $\begin{array}{c}74.74 \\
2,249 \\
68,770\end{array}$ & $\begin{array}{c}3.01 \\
2,244 \\
60,190\end{array}$ & $\begin{array}{c}73.32 \\
306 \\
11,000\end{array}$ & $\begin{array}{c}2.74 \\
306 \\
9,778\end{array}$ & $\begin{array}{c}407.63 \\
306 \\
11,000\end{array}$ & $\begin{array}{c}26.73 \\
306 \\
10,984\end{array}$ & $\begin{array}{c}0.46 \\
306 \\
8,954\end{array}$ \\
\hline
\end{tabular}

Notes: This table reports results from estimating the impact of robotic adoption on the characteristics of prostate cancer patients. Panel A reports the "first stage" results from estimating equation 1 and differs only from Table 2 because it omits observations (hospital- or market-years) with no prostate cancer patients. Panel B reports the "reduced form" estimates of the same specification with the outcome redefined as the average characteristic of prostate cancer patients. Coefficients in Panels A and B have a log-point interpretation, e.g. a coefficient of 0.2 implies a 20 log point change in volume or the average characteristic. Panel $\mathrm{C}$ reports the ratio of the reduced form estimate to the first stage estimate. These coefficients have an elasticity interpretation, i.e. the elasticity of the average characteristic with respect to volume. In columns 5-7, the outcome is the average characteristic of the patients' hospitals. Columns 5 and 6 measure the hospital's beds and prostate cancer patient volume at baseline (1998) levels. See text for more details. Robust standard errors clustered at the market level in parentheses. Regressions control for year and level (hospital or market) fixed effects. 